This item was submitted to Loughborough's Research Repository by the author.

Items in Figshare are protected by copyright, with all rights reserved, unless otherwise indicated.

\title{
The effect of different post-electroplating surface modification treatments on tin whisker growth
}

PLEASE CITE THE PUBLISHED VERSION

https://doi.org/10.1080/00202967.2019.1587263

\section{PUBLISHER}

Taylor and Francis ( Institute of Materials Finishing

\section{VERSION}

AM (Accepted Manuscript)

\section{PUBLISHER STATEMENT}

This is an Accepted Manuscript of an article published by Taylor \& Francis in Transactions of the IMF on 12 May 2019, available online: http://www.tandfonline.com/10.1080/00202967.2019.1587263.

\section{LICENCE}

CC BY-NC-ND 4.0

\section{REPOSITORY RECORD}

Haspel, D., Mark Ashworth, Geoffrey Wilcox, Xujin Bao, and Roger J. Mortimer. 2019. "The Effect of Different Post-electroplating Surface Modification Treatments on Tin Whisker Growth". Loughborough University. https://hdl.handle.net/2134/37061. 


\title{
THE EFFECT OF DIFFERENT POST-ELECTROPLATING SURFACE MODIFICATION TREATMENTS ON TIN WHISKER GROWTH
}

\author{
D.M. Haspel ${ }^{1,4}$, M.A. Ashworth², G.D. Wilcox², X. Bao² \& R.J. Mortimer ${ }^{3}$ \\ 1.-Plymouth Electron Microscopy Centre, University of Plymouth, PL4 8AA, UK.
}

2.-Deparment of Materials, Loughborough University, LE11 3TU, UK

3.-Department of Chemistry, Loughborough University, Loughborough, Leicestershire, LE11 3TU, UK.

\section{4.-e-mail: dan.haspel@plymouth.ac.uk}

\begin{abstract}
There are very few studies that have investigated directly the effect of an oxide film on tin whisker growth, since the 'cracked oxide theory' was proposed by Tu in 1994. The current study has investigated the effect of both a molybdate conversion coating and a tungstate conversion coating on tin whisker growth from SnCu electrodeposits on $\mathrm{Cu}$, and compared it with that from an electrochemically-formed oxide produced from a potassium bicarbonate-potassium carbonate electrolyte. X-ray photoelectron spectroscopy (XPS) has been used to investigate the effect of both immersion time and applied potential on the thickness and composition of the oxide film. The XPS studies show that the oxide film formed using either of the conversion coating baths is significantly thicker than that produced from the potassium bicarbonate-potassium carbonate bath. Initial observations suggest that both the tungstate-based conversion coatings and the molybdate-based conversion coatings significantly reduce whisker growth by over $80 \%$ for all conversion coating systems compared with a native air-formed oxide and provide improved mitigation compared with the electrochemically formed oxides previously investigated.
\end{abstract}

Key words: Tin, conversion coating, molybdate, tungstate, electrochemical oxidation, electrodeposition, whisker growth

\section{INTRODUCTION}

A tin whisker is commonly a filamentary growth of pure tin, which will generally grow from thin tin electroplate, and can grow up to lengths of a few millimetres, though more commonly they will grow up to a few $100 \mu \mathrm{m}$ 's [1]. Tin whiskers can cause major reliability problems in high value, long-life electronics, such 
as rocket guidance systems and aerospace systems, mainly due to them growing from one surface and coming into contact with another, adjacent surface, resulting in a short circuit and subsequent electronic failure [2]. Electronics can also fail if whiskers are broken off and subsequently land across adjacent terminals. If the current in the circuit is high enough, the whisker can volatilise into a conductive metal gas, which could result in the creation of a metal vapour arc [3]. The metal vapour arc reaction can generate sufficiently high temperatures to melt metals and incinerate polymers.

One of the most significant problems is the unpredictability of whisker growth and their varying incubation periods, which causes concern with regards to the long-term reliability of electronic components [4]. Moreover, there is, currently, no one accepted whisker growth mechanism; though there are a number of theories and some commonly agreed factors that affect whisker growth $[1,5,6]$.

Until recently, whisker growth was successfully mitigated through the alloying of tin with lead $[7,8]$. However, due to EU legislation (e.g. RoHS) [9], the use of lead has been restricted, therefore alternative strategies are required to mitigate whisker growth from both lead-free solderable surfaces and lead-free solid solders. Currently, there are a number of different strategies, including post-electroplating annealing, alloying (Sn-Ag and $\mathrm{Sn}-\mathrm{Bi}[10])$, applying a polymeric coating and the use of an electroplated underlay to prevent intermetallic formation [11].

Until recently, there has been little research into the role of the oxide layer in whisker growth. Tu's cracked oxide theory [12-15] proposed that the tin oxide film played a crucial role in the growth of tin whiskers and that a very thick oxide would physically block the growth of whiskers by reducing the risk of localised oxide cracking at weak points in the film. If the protective oxide film is not sufficiently thick, it may be broken at certain weak points and it is from these locations that whiskers grow subsequently to relieve the stress $[16,17]$. In the absence of an oxide film, whisker growth would not occur as the deposit would be able to relieve stress by uniform creep [18], as demonstrated for by Chang and Vook [19] for hillock growth from aluminium. However, Moon et al [20] showed that whisker growth occurred on Sn-Cu electrodeposits that had been stored for 9 days under a vacuum following removal of the surface oxide by ion beam sputtering.

Evidence to support Tu's theory was provided by Su et al [21], [22] who produced samples with a $200 \mathrm{~nm}$ thick sputter deposit of tin oxide that was given a pre-defined array of circular-shaped 'weak spots' using lithography. It was observed that whiskers would preferentially grow from some, but not all, of these predefined 'weak points', demonstrating that although a weak oxide was necessary for whisker growth, the underlying grain structure was also important. Furthermore, results showed that an increased number of 
'weak spots' resulted in increased number of whiskers, however, these were shorter than those developed on samples with fewer 'weak points'. Analysis of the residual stress levels with the coatings using synchrotron radiation $\mathrm{x}$-ray measurements revealed that the average compressive stress developed within the coatings because of intermetallic growth was independent of the number of weak points present in the coating. Wu and Ding [23] investigated the influence of a coating of tin oxide nano particles on whisker growth from surface treated electroplated tin films on copper. Their results showed that the nano particle coating introduced discontinuities (i.e. 'weak spots') into the native oxide film thereby promoting the growth of hillocks rather than long filament whiskers.

In previous studies by the current authors [24,25], it was observed that an electrochemically formed tin oxide greatly reduced the growth of whiskers and that increasing the thickness of the tin oxide film promoted further reductions in whisker growth.

Conversion coatings are a form of passivation treatment and consist of converting the substrate metal surface from an active to a passive state [26]. A conversion coating can also be thought of as a mixed oxide coating as it consists of a mixture of corrosion products from the substrate metal and reduced species from the ions in the electrolyte. Generally, conversion coatings are significantly thicker than a native air-formed oxide, however, they are prone to cracking and flaking. Two non-chromate conversion coatings specifically developed for tin surfaces are investigated in this paper; a molybdate-based conversion coating [26] and a tungstate-based conversion coating [27]. The effect of processes parameters on the composition and thickness of the conversion coatings was determined and the effect of the resultant oxide coatings on whisker growth investigated.

\section{EXPERIMENTAL METHOD}

\subsection{Electrodeposition of Sn and Sn-Cu Alloy}

For initial conversion coating trials, $5 \mu \mathrm{m}$ of pure $\mathrm{Sn}$ was electrodeposited onto Cu substrates (Advent Research Materials, 99.9\% purity, $0.4 \mathrm{~mm}$ thick) at a current density of $20 \mathrm{~mA} \mathrm{~cm}^{-2}$, using a bright acid Sn electroplating bath. For subsequent whisker growth trials, a $\mathrm{Sn}-\mathrm{Cu}$ alloy was electroplated onto $\mathrm{Cu}$. The electroplating solution contained $60 \mathrm{~g} \mathrm{~L}^{-1}$ tin sulphate (Sigma Aldrich), $70 \mathrm{ml} \mathrm{L}^{-1}$ sulphuric acid (SG 1.83, Fisher Scientific) and $40 \mathrm{ml} \mathrm{L}^{-1}$ Tinmac Stannolyte (MacDermid), a propriety additive that acts as a brightener. For the electrodeposition of $\mathrm{Sn}-\mathrm{Cu}$ alloys, the $\mathrm{Sn}$ electroplating bath was modified by the addition of $\mathrm{Cu}$ ions at a concentration of $10 \mathrm{mmol} \mathrm{L}^{-1}$, using copper sulphate (Fisher Scientific). Electrodeposition of $2 \mu \mathrm{m} \mathrm{Sn-Cu}$ onto 
Cu was carried out at a current density of $10 \mathrm{~mA} \mathrm{~cm}{ }^{-2}$, which resulted in a uniform electrodeposit with a $\mathrm{Cu}$ content of $\sim 1$ wt.\%.

Test coupons had dimensions of $2 \times 4 \times 0.04 \mathrm{~cm}$ and were masked with chemically inert tape, which resulted in an electroplated area of $2 \times 2 \mathrm{~cm}$. The coupons were used in their as-received condition with no additional grinding or polishing. Electrodeposition of pure Sn was carried out using a 99.95\% Sn foil anode (Advent Research Materials, $0.25 \mathrm{~mm}$ ), whilst electrodeposition of the $\mathrm{Sn}-\mathrm{Cu}$ was carried out using a $50 \times 50 \mathrm{~mm}$ platinised titanium mesh anode, $1 \mu \mathrm{m}$ Pt coating (Ti-Shop). Prior to electrodeposition, all coupons were degreased with acetone (Fisher Scientific), cleaned using a detergent solution, rinsed with deionised water and dried using hot air. Immediately prior to electrodeposition, the coupon was pickled for $60 \mathrm{~s}$ in a $20 \% \mathrm{v} / \mathrm{v}$ solution of sulphuric acid (SG 1.83, Fisher Scientific), rinsed with deionised water and dried using hot air. Pickling was carried out just prior to electroplating.

\subsection{Preparation of Electrolytes for Surface Modification Treatment}

Three solutions were prepared for the post-electroplating surface modification treatments. One solution was for electrochemical oxidation and the other two solutions were used to generate conversion coatings. Electrochemical oxidation was carried out using a pH 8.9 potassium bicarbonate-potassium carbonate solution ( $0.75 \mathrm{~mol} \mathrm{~L}^{-1}$ of potassium bicarbonate and $0.05 \mathrm{~mol} \mathrm{~L}^{-1}$ of potassium carbonate, both Sigma Aldrich). The solution was prepared using deionised water and the $\mathrm{pH}$ was adjusted to 8.9 , using additions of sodium hydroxide (Fisher Scientific).

For the molybdate conversion coating an acidic sodium molybdate solution (10 $\mathrm{g} \mathrm{L}^{-1}$ sodium molybdate, Sigma Aldrich) was used. The solution was prepared using deionised water and the $\mathrm{pH}$ was adjusted to $\sim 3$, using additions of hydrochloric acid (SG 1.18, Fisher Scientific).

For the tungstate conversion a sodium tungstate solution $\left(0.1 \mathrm{~mol} \mathrm{~L}^{-1}\right.$ sodium tungstate and $10 \mathrm{~g} \mathrm{~L}^{-1}$ sodium tetraborate, both Sigma Aldrich) was used. The solution was prepared using deionised water and the $\mathrm{pH}$ was not altered $(\sim \mathrm{pH} 9)$.

\subsection{Surface Modification Treatment}

All surface modification treatments were carried out immediately after electrodeposition of the $\mathrm{Sn}$ or $\mathrm{Sn}-\mathrm{Cu}$ coating using, if required, a Solartron SI 1286 Electrochemical Interface potentiostat and the 3-electrode cell described previously [24,25]. 


\subsubsection{Electrochemical Oxidation}

Electrochemical oxidation treatments were carried out in the potassium bicarbonate-potassium carbonate solution. Following immersion of the coupon into the electrolyte solution, the $\mathrm{Sn}$ or $\mathrm{Sn}$-Cu electrodeposit was initially held at a potential of $-1.5 \mathrm{~V}$ vs. $\mathrm{Ag} / \mathrm{AgCl}$ to reduce the pre-existing oxide. When hydrogen evolution was observed, the surface was agitated using a pipette filled with the electrolyte solution to remove any bubbles that were present and the potential was increased to $2 \mathrm{~V} v \mathrm{vs}$. $\mathrm{Ag} / \mathrm{AgCl}$. For each test coupon a charge of $60 \mathrm{mC} \mathrm{cm}^{-2}$ was passed.

\subsubsection{Conversion Coatings}

For molybdate conversion coatings, samples were immersed in solutions, with a $\mathrm{pH}$ of 3.13 , for times of 110 minutes. Pulsed current trials were also carried out using the parameters shown in Table 1. Samples were also held at potentials ranging from -0.45 to $-0.75 \mathrm{~V} v$ s. $\mathrm{Ag} / \mathrm{AgCl}$ for 5 minutes.

For tungstate conversion coatings, a modified version of the pulsed current method used by Van De Leest and Krijl [27] was used. Pulsed current densities ranging from \pm 2.5 to $\pm 10 \mathrm{~mA} \mathrm{~cm}^{-2}$ were used at a frequency of $0.5 \mathrm{~Hz}$ for square wave cycles ranging in number from $30-300$. Three sets of experiments were carried out to optimise the tungstate process and the full set of parameters used are given in Table 2.

\subsection{Characterisation of Conversion Coatings}

The effect of process variables on the composition and thickness of the molybdate and tungstate coatings was investigated by $x$-ray photoelectron spectroscopy (XPS) using a Thermo-Scientific K-Alpha x-ray photoelectron spectrometer. Sputter depth profiling was carried out using $1 \mathrm{keV}$ argon ions with an estimated etch rate of $\sim 0.28 \mathrm{~nm} \mathrm{~s}^{-1}$ with respect to $\mathrm{Ta}_{2} \mathrm{O}_{5}$. XPS analysis was carried out within 24 hours of electrodeposition and conversion coating, unless otherwise stated. The sputter time taken to reach $50 \%$ of the surface oxygen content was used to compare the thickness of the oxide coatings produced by the different process variations.

The topography of the conversion coatings was investigated using scanning electron microscopy (SEM) and optical microscopy. SEM analysis was carried out using a Carl Zeiss Leo 1530 VP field emission gun SEM (FEGSEM) at an operating voltage of $10 \mathrm{kV}$ and a working distance of $\sim 11 \mathrm{~mm}$. Optical microscopy was carried out using a Leica DMi8 optical microscope. 
The thickness of the conversion coating and the microstructure of the electroplated $\mathrm{Sn}-\mathrm{Cu}$ coating was investigated using a FEI Nova 600 Nanolab Dual Beam focussed ion beam milling scanning electron microscopy (FIB-SEM) using the method previously described [25].

\subsection{Tin Whisker Growth Studies}

The effect of the oxide coatings on subsequent tin whisker growth was assessed using $2 \mu \mathrm{m} \mathrm{Sn-Cu}$ electrodeposits on $\mathrm{Cu}$. To study whisker growth on electrochemically formed oxides, 26 samples were produced, of which 13 were left to develop native air-formed oxides (untreated) and 13 were electrochemically oxidised. Periodically, three untreated samples and three electrochemical oxidised samples were randomly selected for analysis to investigate the time dependence of whisker growth and also to provide a benchmark for the conversion coated samples. The time dependent growth of the oxide film was also investigated by analysing both untreated and electrochemically oxidised samples at the same time intervals as the whisker growth samples. For each specific conversion coating treatment three identical test samples were prepared. In each case, uncoated control samples were left to develop native air-formed oxides (untreated) for comparison. After electrodeposition and the formation of the oxide coating, the samples were stored at room temperature $\left(\sim 20^{\circ} \mathrm{C}\right)$. The growth of the tin whiskers was studied periodically using both optical microscopy and SEM. The whisker density and the longest apparent whisker length (per frame) were measured using an optical microscope with an objective magnification of $\times 20$ and a frame area of $\sim 0.57 \mathrm{~mm}^{2}$. The method used to measure the apparent whisker length is shown in Fig.1, whereby Fig.1a shows the actual length of the whisker and Fig.1b shows the apparent whisker length.

\section{RESULTS AND DISCUSSION}

\subsection{Characterisation of Molybdate Conversion Coatings}

The depth profiles in Fig.2 (a) \& (c) show that the conversion coating is comprised of molybdenum and oxygen with a region enriched in tin oxide present at the interface between the coating and the Sn metal. For the sample immersed for 5 min (Fig.2a), the oxygen and molybdenum contents suggest that the stoichiometry of the coating corresponds to $\mathrm{MoO}_{2}$ whilst the outer surface of the conversion coating may correspond to $\mathrm{MoO}_{3}$. A similar change in oxidation state for molybdenum between the outer surface and the remainder of the coating was also observed previously [28-30]. This change in oxidation state is shown in Fig.2 (b) which plots the binding energy of the molybdenum peak as a function of sputter time. The binding energy of the molybdenum peak at the outer surface is $232.11 \mathrm{eV}$, which lies within the binding energy range given in the literature (232.1-233.25 eV) for $\mathrm{MoO}_{3}$ [31]; whilst that within the remainder of the coating (229.04-229.21 
$\mathrm{eV}$ ) lies within the reported range given in the literature (228.8-232.0 eV) for $\mathrm{MoO}_{2}$ [31]. The binding energy data suggests that the molybdenum was further reduced to metallic Mo at the approximate position of the oxide-metal interface. The presence of Mo in the coating may not be valid as the coating being produced was a molybdate coating and not a metallic coating. The presence of pure Mo is most likely due to sputter induced reduction, which will be discussed later on. These depth profiles were typical for the majority of the molybdate coatings.

The coating thickness was seen to increase by $\sim 15 \mathrm{x}$ for the sample produced at $-0.75 \mathrm{~V} \mathrm{vs.} \mathrm{Ag} / \mathrm{AgCl}$ in comparison with the sample immersed for $5 \mathrm{~min}$ (shown in Fig.2c), although a similar trend was observed in the binding energy of the molybdenum peak. However, there is a gradual reduction in the oxygen content up to $\sim 1000$ s of sputter, from $\sim 60$ at. $\%$ at the surface to $\sim 50$ at. $\%>1000 \mathrm{~s}$; beyond 1000 s the oxygen content remains constant, which would suggest a stoichiometry of MoO. This gradual reduction in oxygen content could be due to prolonged argon ion sputtering causing reduction of the molybdenum oxide. Molybdenum reduction, as a result of the prolonged sputter, is also reflected in Fig.2 (d) which shows that the molybdenum peak binding energy continually decreases throughout the thickness of the coating.

Table 3 shows that all of the molybdate conversion coatings are significantly thicker than the thickest electrochemical oxide previously produced [25].Table 3 also shows that the molybdenum content within the oxide coating is similar for all the samples, however, for the sample produced at $-0.75 \mathrm{~V} \mathrm{vs}$. $\mathrm{Ag} / \mathrm{AgCl}$ the Mo content increases progressively through the bulk of the coating (Fig.2). This may be due to sputter induced reduction of the molybdenum oxide [28-30], which may also cause preferential sputtering of the oxygen. Table 3 also shows that there is a significant thickness difference between the two samples produced at the most cathodic formation potentials $(-0.6$ and $-0.7 \mathrm{~V} \mathrm{vs}$. $\mathrm{Ag} / \mathrm{AgCl})$ and the rest of samples. Optical microscopy shows that both these coatings have a high density of cracking; shown in Fig. 3 for the coating produced at -0.6 $\mathrm{V} v \mathrm{vs} . \mathrm{Ag} / \mathrm{AgCl}$. The observed cracking may be due to increased tensile stress induced by film thickness and/or the drying process, as suggested by Zhang et al [32] and da Silva et al [33]. During the drying process the moisture is removed from the coating, which causes the coating to shrink; this shrinkage generates tensile stresses within the coating that can subsequently cause cracking.

\subsection{Characterisation of Tungstate Conversion Coatings}

The depth profile in Fig.4 shows that the coating consists mainly of tin oxide with only a small amount of tungsten present throughout; a slightly increased tungsten content ( 4 at.\%) is observed near the surface of the coating. All the tungstate depth profiles measured from the tungstate conversion coated samples were similar in appearance, irrespective of processing parameters, and the results are summarised in Table 4 . It 
can be seen from Table 4 that as the current density is increased the thickness of the conversion coating is also increased, which is to be expected as the total charge passed increases. Table 4 also shows that as the number of cycles increases the thickness of the conversion coating increases. It might further be expected that passing an equivalent charge would result in conversion coatings of similar thickness, however, EC.3 was significantly thicker than EC.1 and EC.2, which were similar in thickness. This may arise from oxide formation at at $\pm 10 \mathrm{~mA} \mathrm{~cm}^{-2}$ being more effective at creating a thicker oxide layer than at either $\pm 2.5 \mathrm{~mA} \mathrm{~cm} \mathrm{cor}^{-2} \pm 5 \mathrm{~mA}$ $\mathrm{cm}^{-2}$.

Table 4 shows that, although a higher current density is able to produce a thicker coating for an equivalent charge passed, there is a limit to how much charge can be passed before the coating quality deteriorates, as shown in Fig.5. At the higher current density, more gas bubbles were formed at the sample surface, compared with the lower current density, which may have hindered or prevented the deposition of the oxide coating and resulted in the formation of regions where the coating has either fully flaked off to expose the underlying tin or is thinner than the majority of the coating. Such regions can be considered as 'weak points' in the oxide coating. Results show that using a current of density of $\pm 10 \mathrm{~mA} \mathrm{~cm}{ }^{-2}$ there is a limit of $\sim 45$ cycles before the coating quality is reduced, whilst the limit for a current density of $\pm 5 \mathrm{~mA} \mathrm{~cm}^{-2}$ is between 150 and 180 cycles. This indicates that thicker coatings may be produced at lower current densities since increased charge may be passed before the coating quality deteriorates.

Optical microscope analysis was carried out on selected tungstate samples to study the surface of the coating. Fig. 6 shows the appearance of the coating 3 months after deposition, for samples processed at $\pm 10 \mathrm{~mA} \mathrm{~cm}$ ${ }^{2}$ for 45 cycles, $\pm 5 \mathrm{~mA} \mathrm{~cm}^{-2}$ for 90 cycles and $\pm 5 \mathrm{~mA} \mathrm{~cm}^{-2}$ for 150 cycles. As observed from Fig. 5 the cycle limit for samples processed at $\pm 10 \mathrm{~mA} \mathrm{~cm}^{-2}$ is 45 cycles and Fig.6a confirms that a high number of 'weak points' are present in the coating. In comparison the tungstate coating produced at $\pm 5 \mathrm{~mA} \mathrm{~cm}^{-2}$ for 90 cycles (Fig.6b) showed no such 'weak points'. 'Weak points' were, however, present on the tungstate coating produced at $\pm 5 \mathrm{~mA} \mathrm{~cm}^{-2}$ for 150 cycles (Fig.6c), though far fewer than were observed on the sample produced at $\pm 10 \mathrm{~mA}$ $\mathrm{cm}^{-2}$ for 45 cycles. The impact of these 'weak points' on the ability of the coating to mitigate whisker growth is discussed in a later section.

SEM analysis was carried out on the tungstate samples to study the surface morphology of the coating in more detail. Fig.7 shows the appearance of the coating for samples processed using different conditions; Figs.6 (a) and (b), which were processed at $\pm 10 \mathrm{~mA} \mathrm{~cm}{ }^{-2}$ for 30 cycles and $\pm 5 \mathrm{~mA} \mathrm{~cm}^{-2}$ for 60 cycles, respectively, both showed a uniform surface with no evidence of cracking. In comparison samples processed at $\pm 10 \mathrm{~mA} \mathrm{~cm}^{-2}$ for 90 and 150 cycles (Fig.7 c and d respectively), both showed a surface with a large number 
of cracks and areas, which varied in size, where the oxide was either thinner or completely flaked off to expose the underlying $\mathrm{Sn}$ (as shown in Fig.7e, $\pm 10 \mathrm{~mA} \mathrm{~cm}^{-2}$ for 90 cycles). Compared with the cracking on the molybdate samples, that on the tungstate samples is much finer, in terms of crack width, (Fig.7 c and d) and not visible under the optical microscope at an objective magnification of $\times 20$.

\subsection{Effect of Electrochemical Oxidation on Whisker Growth}

Whisker growth has been evaluated using optical microscopy; three randomly selected samples for the electrochemically oxidised and untreated groups of samples were analysed at each analysis point and the average whisker density calculated. The graph in Fig.8 shows that, for both sets of samples, the whisker density increases progressively with time, however, the presence of the electrochemically formed oxide significantly reduces whisker growth compared with that from the untreated samples that were left to develop a native air-formed oxide.

Fig. 8 shows that the whisker growth for the untreated samples rapidly increases between 14 and 84 days of storage; after which the whisker formation rate reduces. In comparison, the electrochemically oxidised samples showed an increased incubation period prior to the onset of whisker growth, with no significant increase in whisker density until the analysis after $\sim 56$ days storage. For both sets of samples there is a reduced rate of whisker initiation after $\sim 84$ days and most whiskers were formed between $\sim 42-84$ days.

The graph in Fig.9 shows that the thickness of the oxide on the untreated samples steadily increases over time and becomes similar in thickness to that on the electrochemically oxidised samples after $\sim 84$ days of storage; Fig.9 also shows that the thickness of the oxide on the electrochemically oxidised samples remains relatively consistent over time with very little change over a period of 204 days. The increase in oxide thickness for the untreated samples may contribute to the reduced rate of whisker initiation observed after $\sim 84$ days. However, the reduced rate of whisker growth may also be due to a reduced rate of intermetallic compound (IMC) formation, which is a known driving force for whisker growth due to increased compressive stresses in the coating $[1,17,34]$. Stuttle et al [35] showed that after 1 day, IMC growth was observed for pure $\mathrm{Sn}$ on $\mathrm{Cu}$, and after 55 days almost the entire copper surface was covered in IMC growth. This suggested that majority of the IMC growth would occur not long after 55 days, therefore slowing down the driving force for whisker growth; however, the IMCs may continue to grow along the grain boundaries. The coating used in this paper was a $\mathrm{Sn}-\mathrm{Cu}$ alloy which may promote a more rapid formation of IMC due to the presence of copper in the coating itself. The increased incubation period prior to the onset of whisker growth for the electrochemically oxidised samples may be attributed to the increased thickness of the oxide, compared with the untreated samples. 
The longest apparent length of whisker in each frame used to determine whisker density was measured at each time interval and is plotted in Fig.10. For the untreated samples, the results indicate that the whisker length increases gradually over the 220 days of storage but that the rate at which the whiskers grow progressively reduces with time. Compared with the untreated samples, the length of the longest whisker is significantly reduced for the electrochemically oxidised samples throughout the period analysed, with little apparent increase in whisker length between 80 and $~ 220$ days.

Fig.11 shows the change in the distribution of the longest whisker per frame for both electrochemically oxidised and untreated samples, between 14 days and 119 days of storage. After 14 days (Fig.11a) all the measured whiskers were less than $100 \mu \mathrm{m}$ in length for both the untreated samples and the electrochemical oxidised samples. Fig.11a also shows that not only were far fewer whiskers present on the electrochemically oxidised samples compared with the untreated samples but they were all less than $40 \mu \mathrm{m}$ in length. After 119 days (Fig.11b), the whisker distribution for the untreated samples has shifted to much greater lengths and each frame analysed contained a whisker greater than $20 \mu \mathrm{m}$ in length. The whisker length distribution for the untreated samples shows that the majority of the whiskers were greater than $100 \mu \mathrm{m}$ in length after 119 days, whereas after 14 days, no whiskers were greater than $100 \mu \mathrm{m}$ in length. In comparison, for the electrochemically oxidised samples, most of the whiskers were still less than $40 \mu \mathrm{m}$ in length, although the maximum whisker length has increased compared with after 14 days of storage. Fig.11b shows that the whisker lengths on the electrochemically oxidised samples are greatly reduced compared with the untreated samples, thereby significantly reducing the risk of the whiskers bridging a gap between components or connections and causing a short circuit. The reduction in the number of long filament whiskers may be due to the increased incubation period for the electrochemically oxidised samples.

Alternatively, it may suggest that the electrochemical oxide influences the rate at the whiskers grow once the whisker has penetrated the oxide layer. It might be expected that when a whisker penetrates through the oxide film, the whisker would have a similar rate of growth to the untreated samples; therefore, the electrochemical oxide also appears to be having an influence on the driving force for whisker growth as well as inhibiting whisker initiation. It was shown previously that for $\mathrm{Sn}-\mathrm{Cu}$ on $\mathrm{Cu}, \mathrm{IMC}$ growth didn't appear to be influenced by the presence of the electrochemical oxide [25]. In the absence of an oxide film, the surface of the tin serves as a source for vacancies to facilitate tin diffusion through the coating, to support the growth of whiskers [36]. However, the presence of a sufficiently thick oxide may impede diffusion of tin atoms by reducing the number of available surface vacancies [13], therefore slowing the rate at which whiskers may grow. This may suggest that whisker growth on the electrochemically oxidised samples is diffusion limited. 


\subsection{Effect of Molybdate Conversion Coatings on Whisker Growth}

For whisker growth studies, molybdate conversion coatings were produced using three different conditions: 5 minutes immersion, $-0.45 \mathrm{~V}$ vs. $\mathrm{Ag} / \mathrm{AgCl}$ for 5 minutes, and $-0.6 \mathrm{~V}$ vs. $\mathrm{Ag} / \mathrm{AgCl}$ for 5 minutes. Whisker densities were evaluated for 3 samples from each coating treatment after $\sim 7$ weeks storage and an average whisker density was calculated (Fig.12). It was observed that all the conversion coatings significantly reduced whisker growth compared with the untreated samples. Comparison of Fig.12 with Fig.8 shows that both the $5 \mathrm{~min}$ immersion samples and that processed at $-0.45 \mathrm{~V}$ vs. $\mathrm{Ag} / \mathrm{AgCl}$ samples provided increased whisker mitigation compared with the electrochemically formed oxide. From Fig. 8 it can be determined that after 49 days the approximate ratio of whisker density for the untreated samples to the electrochemically oxidised samples was $\sim 8: 1$, whereas the 5 min immersion and $-0.45 \vee$ samples had ratios of $\sim 15: 1$ and $\sim 32: 1$, respectively (Fig.12). This may be due to the increased thickness of the oxide on the molybdate conversion coated samples (given in Table 3) more effectively inhibiting whisker growth.

Although, the molybdate sample produced at $-0.6 \mathrm{~V} \mathrm{vs}$. $\mathrm{Ag} / \mathrm{AgCl}$ showed increased whisker growth compared with the other two molybdate coatings; however, it still brought about a reduction in whisker growth (relative to the native air-formed oxide) comparable to that of the electrochemically oxidised surface (i.e. a reduction of $~ 8: 1)$. The reduced effectiveness of the molybdate conversion coating produced at $-0.6 \mathrm{~V} \mathrm{vs} . \mathrm{Ag} / \mathrm{AgCl}$ is most likely due to the high density of cracks that are present (Fig.3 and Fig.13). It was observed that all the whisker growth initiated at cracks, as shown in Fig.13.

Fig.12 further shows that after 12 weeks of storage all the molybdate coatings are still effectively mitigating whisker growth and performing better than an electrochemically oxidised surface (Fig.8). However, the -0.6 $\checkmark$ molybdate samples show a slightly increased rate of whisker growth compared with the other two molybdate coatings; this is most likely due to the high crack density present in these samples (Fig.3 and Fig.13). No cracks or 'weak points' are observed in the other two molybdate coatings and the whisker density increases at a lower rate. However, compared with the untreated samples the molybdate sample produced at $-0.6 \mathrm{~V}$ vs. $\mathrm{Ag} / \mathrm{AgCl}$ is still mitigating whisker growth as effectively after 12 weeks as it did after 7 weeks, with a whisker density ratio of 8:1 at both time intervals. The two other molybdate coatings produced using 5 min immersion and $-0.45 \mathrm{~V}$ vs. $\mathrm{Ag} / \mathrm{AgCl}$ both show a relative improvement in whisker mitigation compared with the untreated samples, with the whisker density ratios increasing from $15: 1$ to $17: 1$ for the 5 min immersion samples and from $\sim 32: 1$ to $\sim 41: 1$ for the $-0.45 \mathrm{~V}$ vs. $\mathrm{Ag} / \mathrm{AgCl}$ samples. 


\subsection{Effect of Tungstate Conversion Coatings on Whisker Growth}

For whisker growth studies, tungstate conversion coatings were produced using three different conditions: $\pm 10 \mathrm{~mA} \mathrm{~cm}^{-2}$ for 45 cycles, $\pm 5 \mathrm{~mA} \mathrm{~cm}^{-2}$ for 90 cycles and $\pm 5 \mathrm{~mA} \mathrm{~cm}^{-2}$ for 150 cycles. Whisker densities were evaluated for each of the 3 samples prepared for each coating treatment after $\sim 9$ weeks storage and an average whisker density calculated (Fig.14). It was observed that all the conversion coated samples had significantly reduced whisker growth compared with the untreated samples. Comparison of Fig.14 with Fig.8 shows that the tungstate conversion coatings provided increased whisker mitigation compared with the electrochemically formed oxide. After 63 days the approximate ratio of whisker density for the native samples to electrochemically oxidised samples was $\sim 5: 1$ (Fig.8), whereas the least effective of the tungstate samples had a ratio of 36:1 (Fig.14).

Fig.14 shows that after 4 months of storage the tungstate coatings are all still mitigating whisker growth more effectively than an electrochemically oxidised surface (Fig.8). The rate at which the whisker density increases for both $\pm 5 \mathrm{~mA} \mathrm{~cm}^{-2}$ samples reduces after 4 months of storage compared with untreated samples. Both coatings display a similar ability to mitigate whisker growth despite there being a significant difference in coating thickness between them (Table.4). This is most likely due to the coatings produced at $\pm 5 \mathrm{~mA} \mathrm{~cm}^{-2}$ for 150 cycles having 'weak points' (Fig.6c and Fig.15a), from which most of the whisker growth occurs for these samples (Fig.15a); similar observations were made for the samples processed at $\pm 10 \mathrm{~mA} \mathrm{~cm}^{-2}$ for 45 cycles. There were still no 'weak points' observed on the samples produced at $\pm 5 \mathrm{~mA} \mathrm{~cm}{ }^{-2}$ for 90 cycles after 4 months of storage. The tungstate coatings produced at $\pm 10 \mathrm{~mA} \mathrm{~cm}^{-2}$ for 45 cycles become less effective with time, which is most likely due to the high concentration of 'weak points' on the coatings (Fig.6a) from which whisker growth is able to occur (Fig.15a).

The tungstate conversion coated samples produced at $\pm 5 \mathrm{~mA} \mathrm{~cm}{ }^{-2}$ for 150 cycles also possessed regions where the coating thickness was reduced; however, these areas did not appear to be preferential sites for whisker growth after $\sim 9$ weeks of storage. This suggests that these regions were still sufficiently thick enough to mitigate whisker growth for these samples.

\subsection{Summary of the Effect of Oxide Coatings on Whisker Growth}

These results are consistent with those obtained previously $[21,22,24,25]$ and provide further experimental evidence to support Tu's theory that the presence of a thicker oxide serves to mitigate whisker growth [1215]. However, results for the conversion coated samples demonstrate that the quality of the coating is also important since thicker coatings were more likely to contain defects, which results in increased whisker 
growth compared with thinner coatings with fewer or no defects. The study also indicates that the electrochemical oxide also significantly reduces the maximum and average whisker length, which would reduce the risk of a whisker bridging a gap in an electronic component and causing a short circuit. However, it was observed by Su et al [21] that the samples with the fewest pre-defined 'weak points' had longer whiskers compared with the samples with the greatest number of 'weak points'. An understanding of the stress distribution within the tin coating, particularly in the vicinity of whiskers, would be advantageous to elucidate the influence of the oxide coatings on stress generation and relaxation mechanisms within the coating. Synchrotron radiation X-ray studies have been used previously to investigate the development and distribution of compressive stresses within tin coatings [14,18,37-40].

FIB cross-sections were produced to study both the IMC growth in the Sn-Cu coating and the thickness of the conversion coating. The micrographs obtained from these cross-sections (Fig.16) show large area fractions of IMC formation for both a molybdate sample (Fig.16a) and a tungstate sample (Fig.16b), which would suggest that the conversion coatings have little effect on the IMC formation when comparing them to the results obtained previously [25]. This would suggest that they mitigate whisker growth simply by acting as physical barrier in the same way as an electrochemically formed oxide. The thickness for the molybdate conversion coating produced at $-0.6 \mathrm{~V}$ vs. $\mathrm{Ag} / \mathrm{AgCl}$ for $5 \mathrm{~min}$ is $\sim 300 \mathrm{~nm}$ and the thickness for the tungstate conversion coating produced at $10 \mathrm{~mA} \mathrm{~cm}^{-2}$ for 45 cycles is $\sim 240 \mathrm{~nm}$.

The two thinner molybdate coatings showed an improved ability to mitigate whisker growth compared with the electrochemically oxidised samples. This may be attributed to their increased thickness which enables them to physically block whisker growth. Despite being thinner, these two molybdate samples showed improved whisker mitigation compared with the $-0.6 \mathrm{~V}$ molybdate samples, due to the improved quality of the coating and the absence of cracks through which whiskers could grow.

Of the three tungstate samples investigated, that produced at $\pm 5 \mathrm{~mA} \mathrm{~cm}^{-2}$ for 90 cycles mitigated whisker growth the most effectively even though it was the thinnest coating, due to the absence of 'weak points' in the coating.

The molybdate samples produced at $-0.6 \mathrm{~V}$ vs. $\mathrm{Ag} / \mathrm{AgCl}$ and the tungstate samples produced at $\pm 5 \mathrm{ma} \mathrm{cm} \mathrm{cm}^{-2}$ for 150 cycles were of similar thicknesses, however the tungstate samples had far fewer whiskers compared with the molybdate samples. This is due to the molybdate samples having an increased density of cracks in the conversion coating, compared with the tungstate samples which had few 'weak points' in the conversion coating. This highlights that the coating quality is also important when mitigating whisker growth. The results 
also show that the parameters to produce the coating can be optimised to maximise thickness whilst avoiding defects.

\section{CONCLUSIONS}

The following conclusions can be drawn from the results obtained in the current study:

- An electrochemical oxidation treatment has been demonstrated to provide continuous whisker mitigation over a period of 220 days for $2 \mu \mathrm{m}$ Sn-Cu deposits on $\mathrm{Cu}$.

- An electrochemical oxidation treatment not only reduces whisker density but also significantly reduces whisker length compared with an untreated surface.

- Conversion coating treatments may be used to develop oxides that are significantly thicker than those that have been achieved to date by an electrochemical oxidation method.

- Initial observations show that both molybdate and tungstate conversion coatings provide improved whisker mitigation compared with electrochemically oxidised surfaces.

- For the tungstate conversion coated samples, most whiskers were observed to grow from areas of the coating where the oxide was thinner or completely absent ('weak points'). Further optimisation of processing parameters (current density, number of cycles) is required to avoid the formation of 'weak points' in the oxide coating

- Compared with the tungstate conversion coatings, an increased density of long, wide, deep cracks are formed on molybdate conversion coated samples produced at $-0.6 \mathrm{~V}$ and $-0.75 \mathrm{~V}$ vs. $\mathrm{Ag} / \mathrm{AgCl}$, which reduces their ability to mitigate whisker growth.

- For both molybdate and tungstate conversion coatings, a thicker coating doesn't necessarily provide improved whisker mitigation since the presence of defects within the coating will strongly influence its ability to mitigate whisker growth.

- Further studies on the distribution and development of compressive stresses within the tin coatings are suggested as a valuable step towards understanding how post-electroplating surface treatments may affect the development of internal stresses and whisker growth.

\section{ACKNOWLEDGEMENTS}

The authors would like to thank both the UK EPSRC Innovative Electronics Manufacturing Research Centre for funding this research through the WHISKERMIT programme and the Loughborough University Materials 
Research School. The authors would also like thank Sabrina Yan at the Loughborough Materials Characterisation Centre (LMCC) for her assistance with FIB cross-sectioning.

\section{REFERENCES}

[1] G.T. Galyon, Trans. on Elect. Pack. Manu. 28 (2005) 94-122.

[2] S. Mathew, M. Osterman, T. Shibutani, Q. Yu, M. Pecht, in: Proc. IEEE Int. Sym. High Density Packag. Microsyst. Integr., 2007, pp. 1-8.

[3] S. Han, M. Osterman, M. Pecht, SMT Mag. (2012) 48-56.

[4] K.G. Compton, A. Medizza, S.M. Arnold, Corrosion 7 (1951) 327-334.

[5] E. Chason, N. Jadhav, F. Pei, E. Buchovecky, A. Bower, Prog. Surf. Sci. 88 (2013) 103-131.

[6] P. Zhang, Y.M. Zhang, Z.M. Sun, J. Mat. Sci. Tech. 31 (2015) 675-698.

[7] S.M. Arnold, Plating 53 (1966) 96-99.

[8] W.J. Boettinger, C. Johnson, L. Bendersky, K. Moon, M. Williams, G. Stafford, Acta Mater. 53 (2005) 5033-5050.

[9] The European Parliament and The Council of The European Union, Off. J. Eur. Union 46 (2003) L37 1923.

[10] M. Martin, D. Lea, J. Nottay, C. Hunt, Processability of Lead-Free Component Termination Materials, 2001.

[11] M. Osterman, CALCE EPSC (2002).

[12] K.-N. Tu, K. Zeng, Proc. IEEE Electron. Components Technol. Conf. (2002) 1194-1200.

[13] K.-N. Tu, J. Suh, A.T.-C. Wu, N. Tamura, C.-H. Tung, Mat. Trans. 46 (2005) 2300-2308.

[14] K.-N. Tu, C. Chen, A.T. Wu, J. Mat. Sci. 18 (2007) 269-281.

[15] K.-N. Tu, Phys. Rev. 49 (1994) 2030-2034.

[16] K.S. Kumar, L. Reinbold, A.F. Bower, E. Chason, J. Mat. Res. 23 (2008) 2916-2934. 
[17] B.Z. Lee, D.N. Lee, Acta Mater. 46 (1998) 3701-3714.

[18] K.N. Tu, J.C.M. Li, Mater. Sci. Eng. a-Structural Mater. Prop. Microstruct. Process. 409 (2005) 131-139.

[19] C.Y. Chang, R.W. Vook, Thin Solid Films 228 (1993) 205-209.

[20] K.-W. Moon, C.E. Johnson, M.E. Williams, O. Kongstein, G.R. Stafford, C.A. Handwerker, W.J. Boettinger, J. Electron. Mat. 34 (2005) L31-L33.

[21] C.-H. Su, H. Chen, H.-Y. Lee, C.Y. Liu, C.-S. Ku, A.T. Wu, J. Electron. Mat. 43 (2014) 3290-3295.

[22] C.-H. Su, H. Chen, H.-Y. Lee, A.T. Wu, Appl. Phys. Lett. 99 (2011).

[23] A.T. Wu, Y.C. Ding, Microelectron. Reliab. 49 (2009) 318-322.

[24] M.A. Ashworth, D. Haspel, L. Wu, G.D. Wilcox, R.J. Mortimer, J. Electron. Mat. 44 (2015) 442-456.

[25] D.M. Haspel, M.A. Ashworth, L. Wu, G.D. Wilcox, R.J. Mortimer, Trans. IMF 93 (2015) 332-341.

[26] G.D. Wilcox, D.R. Gabe, M.E. Warwick, Corr. Sci. 28 (1988) 577-586.

[27] R.E. Van De Leest, G. Krijl, Thin Solid Films 72 (1980) 237-246.

[28] T.J. Driscoll, L.D. McCormick, W.C. Lederer, Surf. Sci. 187 (1987) 539-558.

[29] D.F. Mitchell, G.I. Sproule, M.J. Graham, Surf. Interface Anal. 15 (1990) 487-497.

[30] L.D. Lopez-Carreno, G. Benitez, L. Viscido, J.M. Heras, F. Yubero, J.P. Espinos, a R. Gonzalez-Elipe, Surf. Interface Anal. 26 (1998) 235-241.

[31] NIST, NIST Stand. Ref. Database 20, Version 20 (n.d.).

[32] S. Zhang, B. Yang, G. Kong, J. Lu, Surf. Interface Anal. (2017).

[33] C.G. da Silva, I.C.P. Margarit-Mattos, O.R. Mattos, H. Perrot, B. Tribollet, V. Vivier, Corros. Sci. 51 (2009) 151-158.

[34] K.-N. Tu, Acta Metall. 21 (1973) 347-354.

[35] C.J. Stuttle, M.A. Ashworth, G.D. Wilcox, R.J. Mortimer, Trans. IMF 92 (2014) 272-281. 
[36] T.A. Woodrow, B.P. Works, Proc. SMTA Int. Conf (2006) 24-28.

[37] W.J. Choi, T.Y. Lee, K.N. Tu, N. Tamura, R.S. Celestre, A.A. MacDowell, Y.Y. Bong, L. Nguyen, Acta Mater. 51 (2003) 6253-6261.

[38] W.J. Choi, T.Y. Lee, K.N. Tu, N. Tamura, R.S. Celestre, A.A. MacDowell, Y.Y. Bong, L. Nguyen, G.T.T. Sheng, in: 52nd Electron. Components Technol. Conf. 2002 Proc., 2002, pp. 628-633.

[39] H. Chen, H.Y. Lee, C.S. Ku, A.T. Wu, J. Mater. Sci. 51 (2016) 3600-3606.

[40] J. Hektor, J.B. Marijon, M. Ristinmaa, S.A. Hall, H. Hallberg, S. Iyengar, J.S. Micha, O. Robach, F. Grennerat, O. Castelnau, Scr. Mater. 144 (2018) 1-4. 
Table 1 Parameters used to produce molybdate conversion coatings using a pulsed current technique

Table 2 Parameters used for the optimisation of the tungstate conversion coating

Table 3 Summary of XPS depth profile measurements for molybdate conversion coated samples

Table 4 Summary of XPS depth profile measurements for tungstate conversion coated samples

Fig.1 Schematic showing how apparent length of whisker is viewed. a) shows the actual length of the whisker and b) shows the apparent length of the whisker

Fig. 2 XPS depth profiles obtained from molybdate conversion coatings with respect to element concentration (top) and molybdenum peak binding energy (bottom): (a) \& (b) 5 minutes immersion and (c) \& (d) produced potentiostatically at $-0.75 \mathrm{~V}$ vs. $\mathrm{Ag} / \mathrm{AgCl}$ for 5 minutes. The $\mathrm{pH}$ of the conversion coating bath was 3.13

Fig.3 Optical micrograph of a molybdate conversion coating produced at $-0.6 \mathrm{~V}$ vs. $\mathrm{Ag} / \mathrm{AgCl}$ for 5 min on pure $\mathrm{Sn}$ after $\sim 2$ months of room temperature storage

Fig.4 XPS depth profile of a tungstate conversion coating formed by a pulsed current method at $\pm 5 \mathrm{~mA} \mathrm{~cm}-2$ for 150 cycles (EC.2)

Fig.5 Photographs of tungstate conversion coatings showing the coating quality. a) $\left.\pm 10 \mathrm{~mA} \mathrm{~cm}^{-2} 30 \mathrm{cycles}, \mathrm{b}\right) \pm 5 \mathrm{~mA} \mathrm{~cm}^{-}$ ${ }^{2} 60$ cycles, c) $\pm 10 \mathrm{~mA} \mathrm{~cm}^{-2} 150$ cycles d) $\pm 5 \mathrm{~mA} \mathrm{~cm}^{-2} 150$ cycles, e) $\pm 10 \mathrm{~mA} \mathrm{~cm}{ }^{-2} 90$ cycles, f) $\pm 5 \mathrm{~mA} \mathrm{~cm}^{-2} 180 \mathrm{cycles} \mathrm{g}$ ) $\pm 10 \mathrm{~mA} \mathrm{~cm}^{-2} 45$ cycles and h) $\pm 5 \mathrm{~mA} \mathrm{~cm}^{-2} 90$ cycles. All coatings were deposited onto $5 \mu \mathrm{m}$ pure $\mathrm{Sn}$

Fig. 6 Optical images of tungstate conversion coatings on $2 \mu \mathrm{m} \mathrm{Sn-Cu} \sim 3$ months after deposition: a) $\pm 10 \mathrm{~mA} \mathrm{~cm}^{-2} 45$ cycles, b) $\pm 5 \mathrm{~mA} \mathrm{~cm}^{-2} 90$ cycles and c) $\pm 5 \mathrm{~mA} \mathrm{~cm}^{-2} 150$ cycles. The arrows indicate 'weak points'

Fig.7 SEM micrographs of tungstate conversion coatings on $5 \mu \mathrm{m}$ pure Sn. a) $\left.\pm 10 \mathrm{~mA} \mathrm{~cm} \mathrm{~cm}^{-2} 30 \mathrm{cycles}, \mathrm{b}\right) \pm 5 \mathrm{~mA} \mathrm{~cm}{ }^{-2} 60$ cycles, c) $\pm 10 \mathrm{~mA} \mathrm{~cm}^{-2} 90$ cycles, d) $\pm 10 \mathrm{~mA} \mathrm{~cm}^{-2} 150$ cycles and e) $\pm 10 \mathrm{~mA} \mathrm{~cm}^{-2} 90$ cycles showing examples of 'weak points' in the conversion coating

Fig.8 Graph comparing the evolution of whisker density with storage time for electroplated Sn-Cu samples left untreated and those electrochemically oxidised at $2 \mathrm{~V}$ vs. $\mathrm{Ag} / \mathrm{AgCl}$

Fig.9 Graph comparing the evolution of oxide thickness, measured using XPS, with storage time for electroplated SnCu samples left untreated and those electrochemically oxidised at $2 \mathrm{~V} v \mathrm{vs} \mathrm{Ag} / \mathrm{AgCl}$

Fig.10 Graph comparing the longest measured apparent whisker length with storage time for untreated and electrochemically oxidised ( $2 \mathrm{~V}$ vs. $\mathrm{Ag} / \mathrm{AgCl}$ ) electroplated $\mathrm{Sn}-\mathrm{Cu}$ samples

Fig.11 Graph showing the whisker distribution of untreated and electrochemically oxidised (2 V vs. $\mathrm{Ag} / \mathrm{AgCl}) \mathrm{Sn}-\mathrm{Cu}$ electroplated samples after (a) 14 days and (b) 119 days of storage

Fig.12 Graph showing the effect of a molybdate conversion coating on whisker growth from electroplated Sn-Cu samples after storage at room temperature

Fig.13 SEM micrograph showing whiskers growing from cracks in the molybdate coating produced at $-0.6 \mathrm{~V} \mathrm{vs}$. $\mathrm{Ag} / \mathrm{AgCl}$ for 5 min on $2 \mu \mathrm{m}$ thick Sn-Cu electroplate

Fig.14 Graph showing the effect of a tungstate conversion coating on whisker growth from electroplated Sn-Cu samples after storage at room temperature 
Fig.15 SEM micrographs showing a high concentration of whisker growth from 'weak points' on tungstate coatings produced at a) $\pm 5 \mathrm{~mA} \mathrm{~cm}^{-2}$ for 150 cycles on $2 \mu \mathrm{m} \mathrm{Sn}$-Cu electroplate and b) $\pm 10 \mathrm{~mA} \mathrm{~cm}^{-2}$ for 45 cycles on $2 \mu \mathrm{m} \mathrm{Sn-Cu}$ electroplate

Fig.16 FIB cross-section $2 \mu \mathrm{m}$ Sn-Cu electrodeposits on $\mathrm{Cu}$, a) molybdate conversion coating produced at $-0.6 \mathrm{~V}$ vs. $\mathrm{Ag} / \mathrm{AgCl}$ for $5 \mathrm{~min}$ after 19 weeks of room temperature storage and b) tungstate conversion coating produced at 10 $\mathrm{mA} \mathrm{cm}{ }^{-2}$ for 45 cycles after $\sim 24$ weeks of room temperature storage 
Table.1

\begin{tabular}{|c|c|c|}
\hline Current Density & Frequency & Number of Square Waves \\
\hline $\pm 10 \mathrm{~mA} \mathrm{~cm}^{-2}$ & $0.5 \mathrm{~Hz}$ & 30 \\
\hline $\pm 5 \mathrm{~mA} \mathrm{~cm}^{-2}$ & $0.5 \mathrm{~Hz}$ & 30 \\
\hline $\pm 2.5 \mathrm{~mA} \mathrm{~cm}^{-2}$ & $0.5 \mathrm{~Hz}$ & 30 \\
\hline $\pm 2.5 \mathrm{~mA} \mathrm{~cm}^{-2}$ & $0.5 \mathrm{~Hz}$ & 120 \\
\hline
\end{tabular}


Table. 2

\begin{tabular}{|c|c|c|c|c|}
\hline Experiment & Trial Number & Current Density & Frequency & $\begin{array}{c}\text { Number of Square } \\
\text { Waves }\end{array}$ \\
\hline \multirow{3}{*}{$\begin{array}{l}\text { Comparison of } \\
\text { Current Density }\end{array}$} & CD.1 & $\pm 2.5 \mathrm{~mA} \mathrm{~cm}^{-2}$ & $0.5 \mathrm{~Hz}$ & 30 \\
\hline & CD.2 & $\pm 5 \mathrm{~mA} \mathrm{~cm}^{-2}$ & $0.5 \mathrm{~Hz}$ & 30 \\
\hline & CD.3 & $\pm 10 \mathrm{~mA} \mathrm{~cm}^{-2}$ & $0.5 \mathrm{~Hz}$ & 30 \\
\hline \multirow{3}{*}{$\begin{array}{l}\text { Comparison of } \\
\text { Number of Cycles }\end{array}$} & NC.1 & $\pm 5 \mathrm{~mA} \mathrm{~cm}^{-2}$ & $0.5 \mathrm{~Hz}$ & 30 \\
\hline & NC. 2 & $\pm 5 \mathrm{~mA} \mathrm{~cm}^{-2}$ & $0.5 \mathrm{~Hz}$ & 90 \\
\hline & NC.3 & $\pm 5 \mathrm{~mA} \mathrm{~cm}^{-2}$ & $0.5 \mathrm{~Hz}$ & 150 \\
\hline \multirow{3}{*}{$\begin{array}{c}\text { Comparison of } \\
\text { Equivalent Charge } \\
\text { Passed }\end{array}$} & EC.1 & $\pm 2.5 \mathrm{~mA} \mathrm{~cm}^{-2}$ & $0.5 \mathrm{~Hz}$ & 300 \\
\hline & EC.2 & $\pm 5 \mathrm{~mA} \mathrm{~cm}^{-2}$ & $0.5 \mathrm{~Hz}$ & 150 \\
\hline & EC.3 & $\pm 10 \mathrm{~mA} \mathrm{~cm}^{-2}$ & $0.5 \mathrm{~Hz}$ & 75 \\
\hline
\end{tabular}


Table. 3

\begin{tabular}{|c|c|c|}
\hline Experiment & $\begin{array}{c}\text { Sputter time to } 50 \% \\
\text { oxygen content }\end{array}$ & $\begin{array}{l}\text { Molybdenum content } \\
\text { at plateau region }\end{array}$ \\
\hline 5 min immersion & $200 \mathrm{~s}$ & 37 at.\% \\
\hline $\pm 5 \mathrm{~mA} \mathrm{~cm}^{-2} 30$ cycles & $340 s$ & 36.5 at.\% \\
\hline $\pm 2.5 \mathrm{~mA} \mathrm{~cm}^{-2} 30$ cycles & $215 \mathrm{~s}$ & 36 at.\% \\
\hline $\begin{array}{c} \pm 2.5 \mathrm{~mA} \mathrm{~cm}^{-2} 120 \\
\text { cycles }\end{array}$ & $440 \mathrm{~s}$ & 37 at.\% \\
\hline$-0.45 \vee 5 \mathrm{~min}$ & $280 \mathrm{~s}$ & 37 at.\% \\
\hline-0.6 V $5 \mathrm{~min}$ & $1085 \mathrm{~s}$ & 40 at. $\%$ \\
\hline$-0.75 \vee 5 \mathrm{~min}$ & $3095 \mathrm{~s}$ & 40-48 at.\% \\
\hline $\begin{array}{c}2 \mathrm{~V} 60 \mathrm{mC} \mathrm{cm}-2 \\
\text { (potassium bath) }\end{array}$ & $27 \mathrm{~s}$ & N/A \\
\hline
\end{tabular}


Table.4

\begin{tabular}{|c|c|c|}
\hline Trial Number & Parameters & $\begin{array}{c}\text { Sputter Time to } 50 \% \\
\text { Oxygen Content }\end{array}$ \\
\hline CD.1 & $\begin{array}{c} \pm 2.5 \mathrm{~mA} \mathrm{~cm}^{-2} \\
30 \text { cycles } \\
\end{array}$ & 130 \\
\hline CD.2 & $\begin{array}{c} \pm 5 \mathrm{~mA} \mathrm{~cm}^{-2} \\
30 \text { cycles }\end{array}$ & 280 \\
\hline CD.3 & $\begin{array}{c} \pm 10 \mathrm{~mA} \mathrm{~cm}^{-2} \\
30 \text { cycles }\end{array}$ & 550 \\
\hline NC.1 & $\begin{array}{c} \pm 5 \mathrm{~mA} \mathrm{~cm}^{-2} \\
30 \text { cycles }\end{array}$ & 275 \\
\hline NC. 2 & $\begin{array}{c} \pm 5 \mathrm{~mA} \mathrm{~cm}^{-2} \\
90 \mathrm{cycles}^{2}\end{array}$ & 680 \\
\hline NC.3 & $\begin{array}{l} \pm 5 \mathrm{~mA} \mathrm{~cm}^{-2} \\
150 \text { cycles }\end{array}$ & 1060 \\
\hline EC.1 & $\begin{array}{c} \pm 2.5 \mathrm{~mA} \mathrm{~cm}^{-2} \\
300 \text { cycles }\end{array}$ & 1085 \\
\hline EC. 2 & $\begin{array}{l} \pm 5 \mathrm{~mA} \mathrm{~cm}^{-2} \\
150 \text { cycles }\end{array}$ & 1085 \\
\hline EC.3 & $\begin{array}{c} \pm 10 \mathrm{~mA} \mathrm{~cm}^{-2} \\
75 \mathrm{cycles}\end{array}$ & 1410 \\
\hline
\end{tabular}


Fig.1

a)

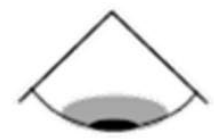

b)

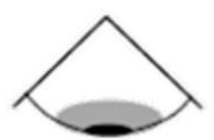

$\downarrow$
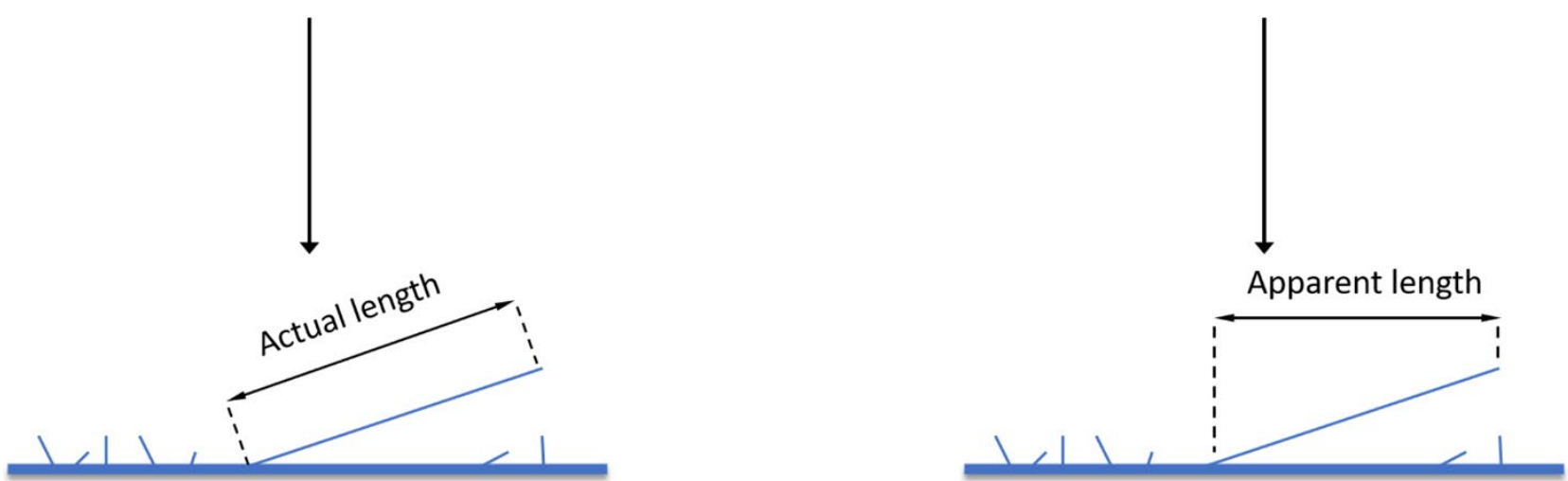
Fig. 2
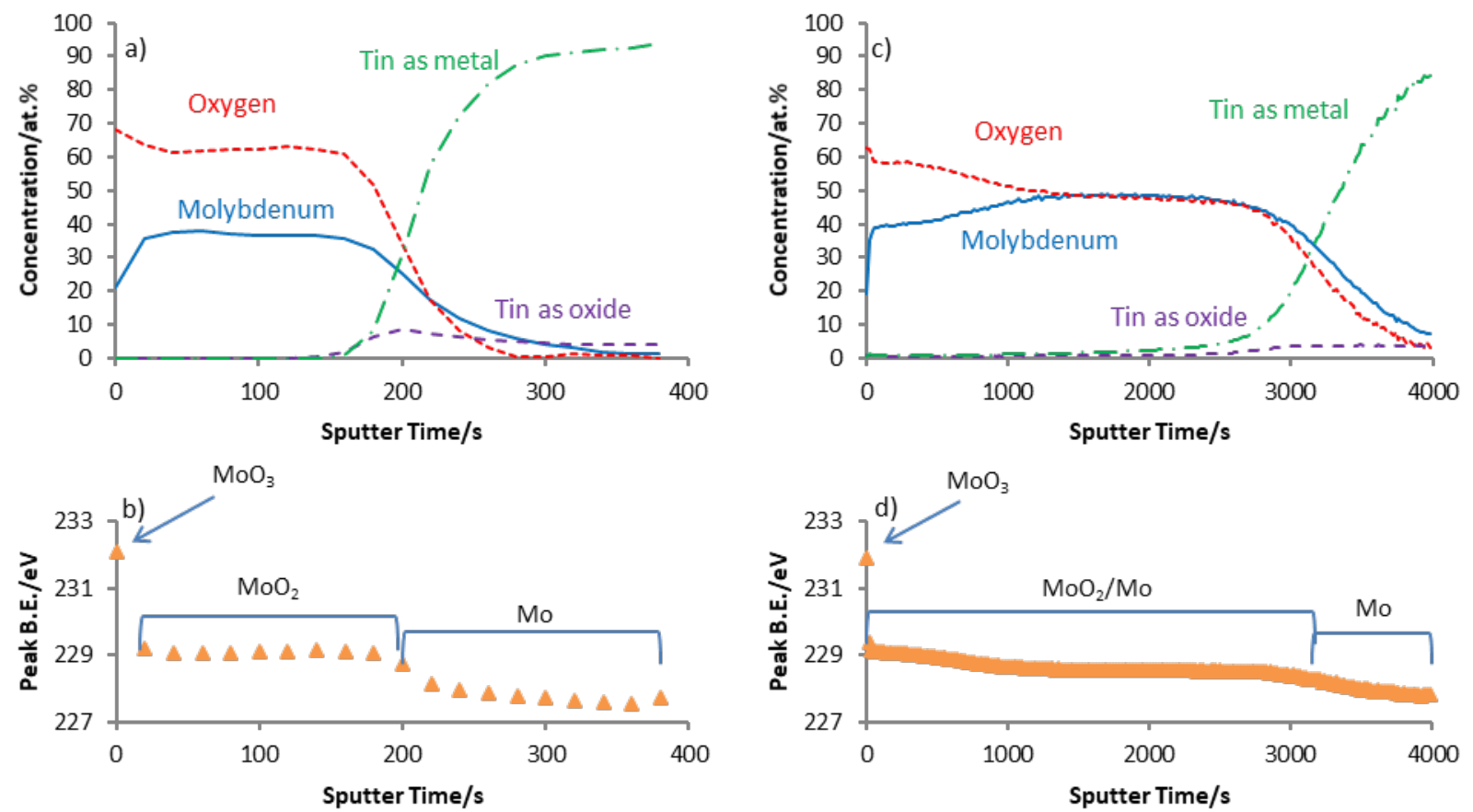
Fig.3

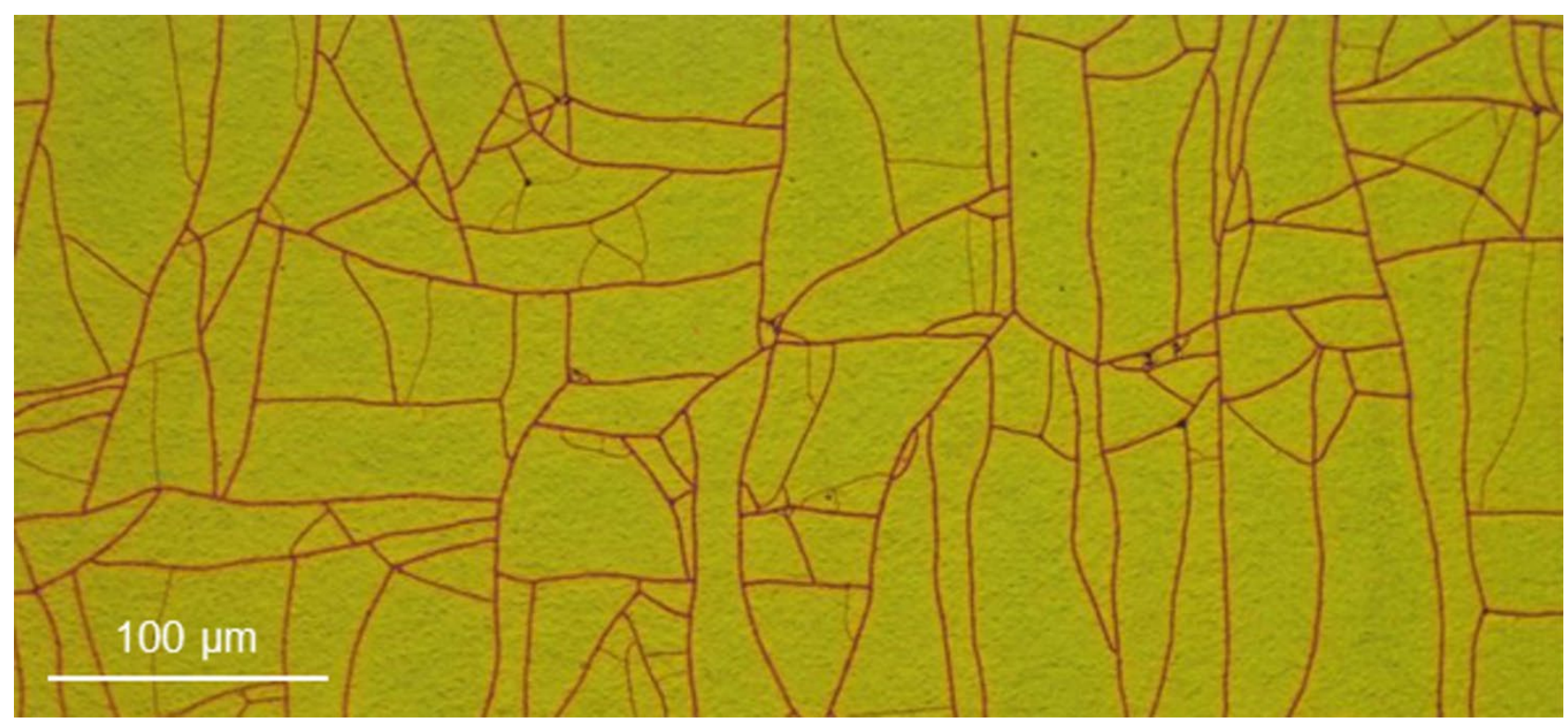


Fig.4

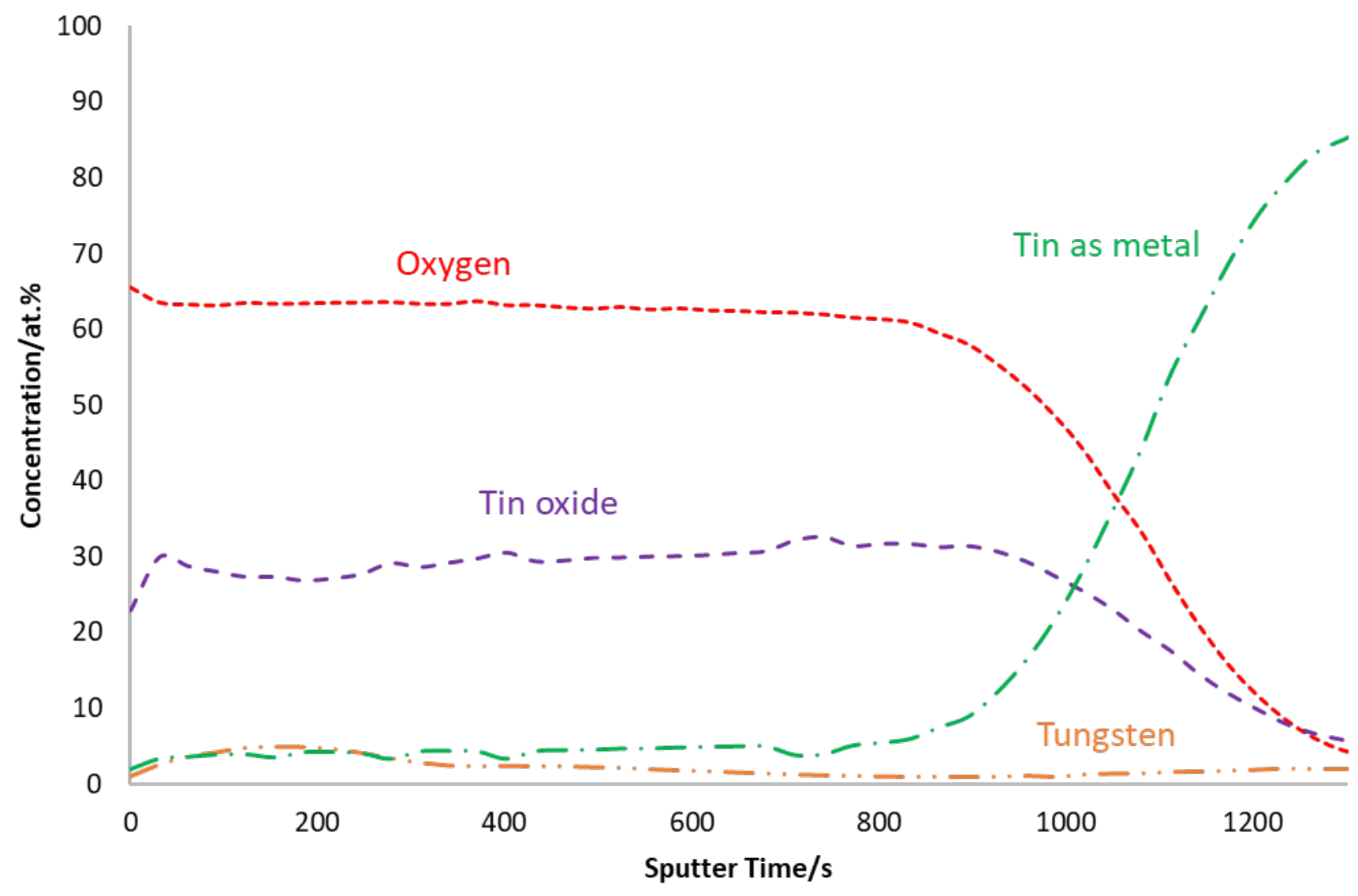


Fig.5
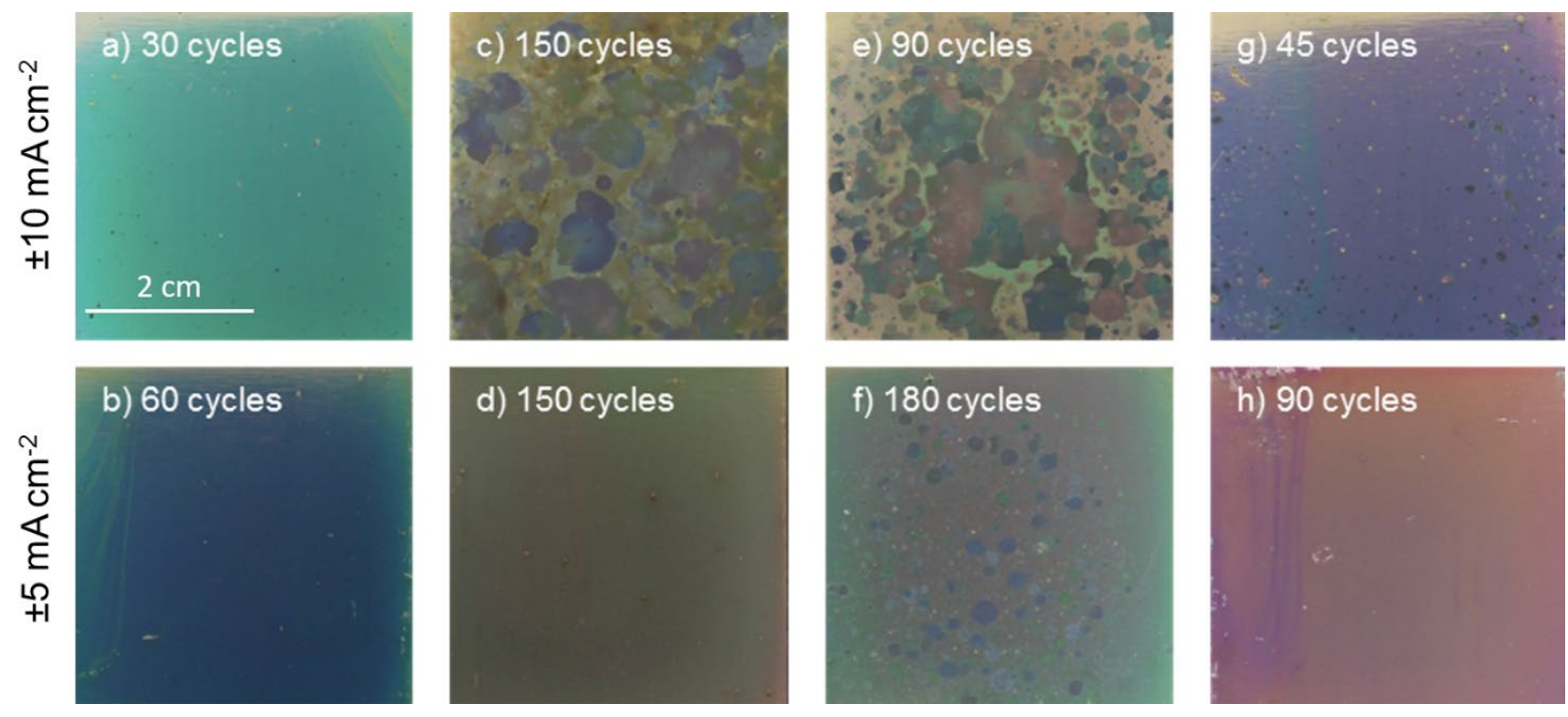
Fig.6
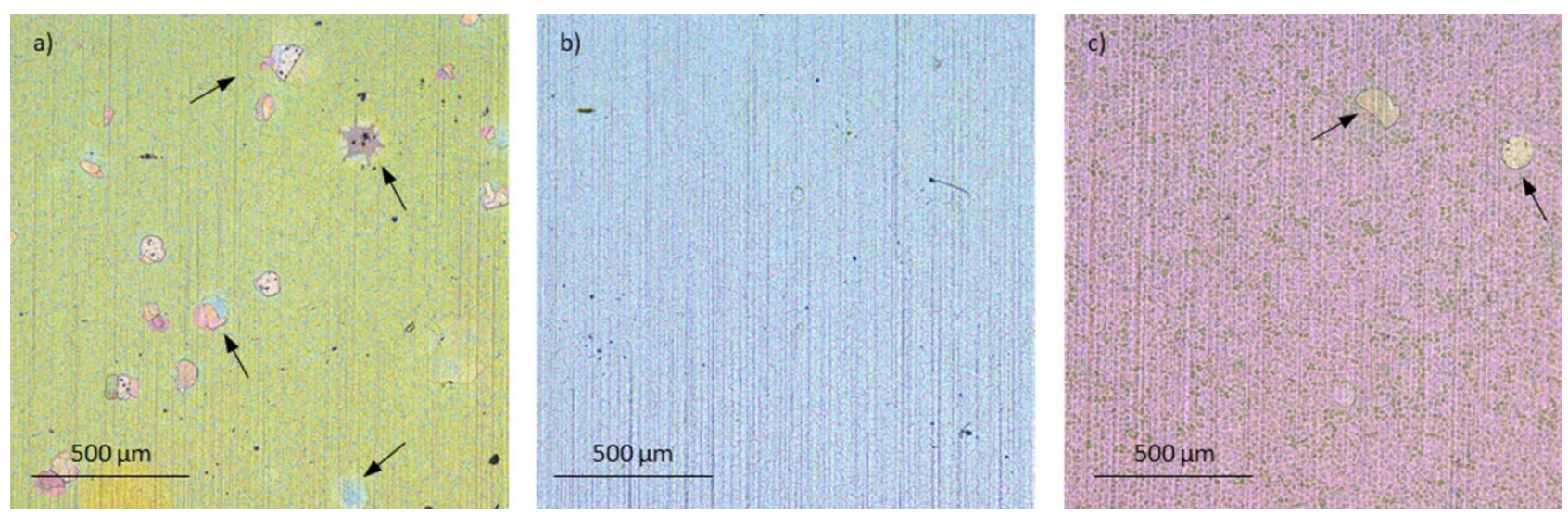
Fig.7
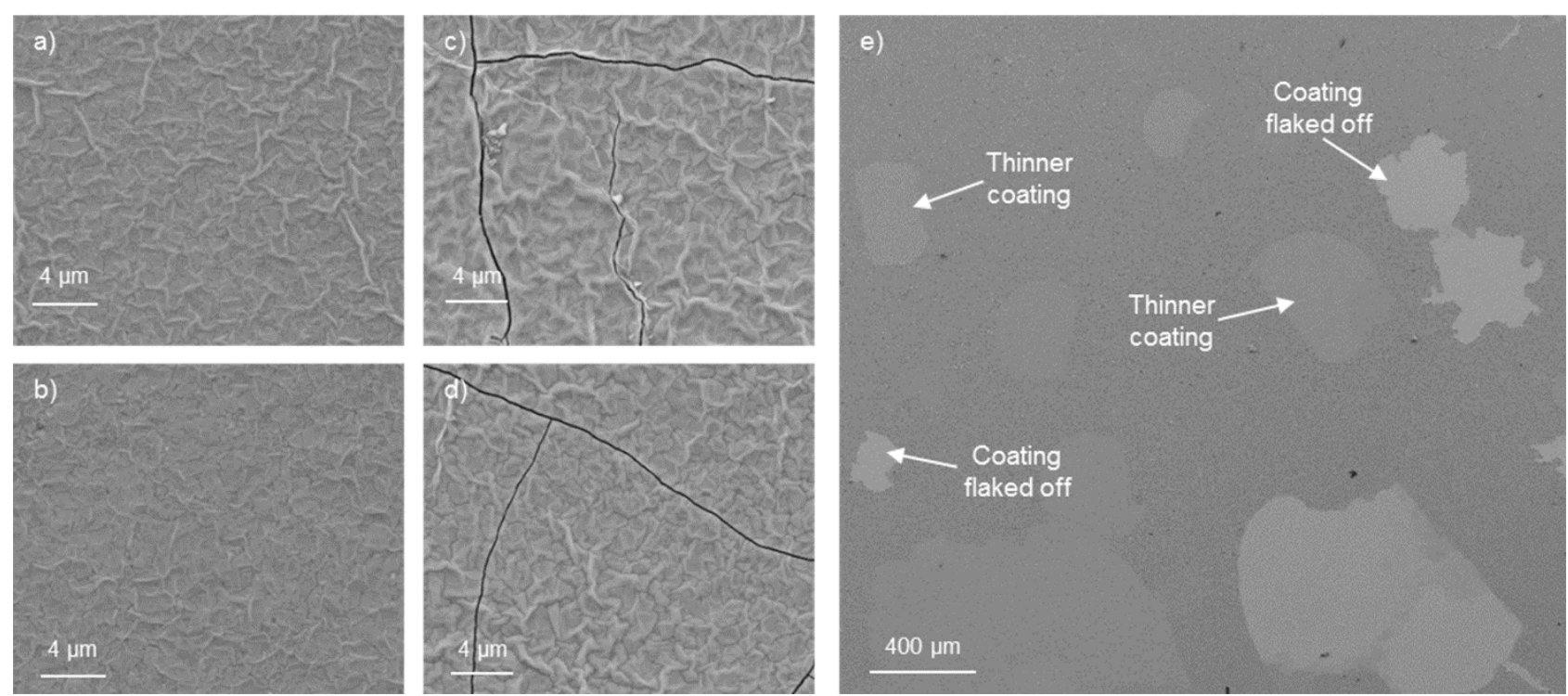
Fig.8

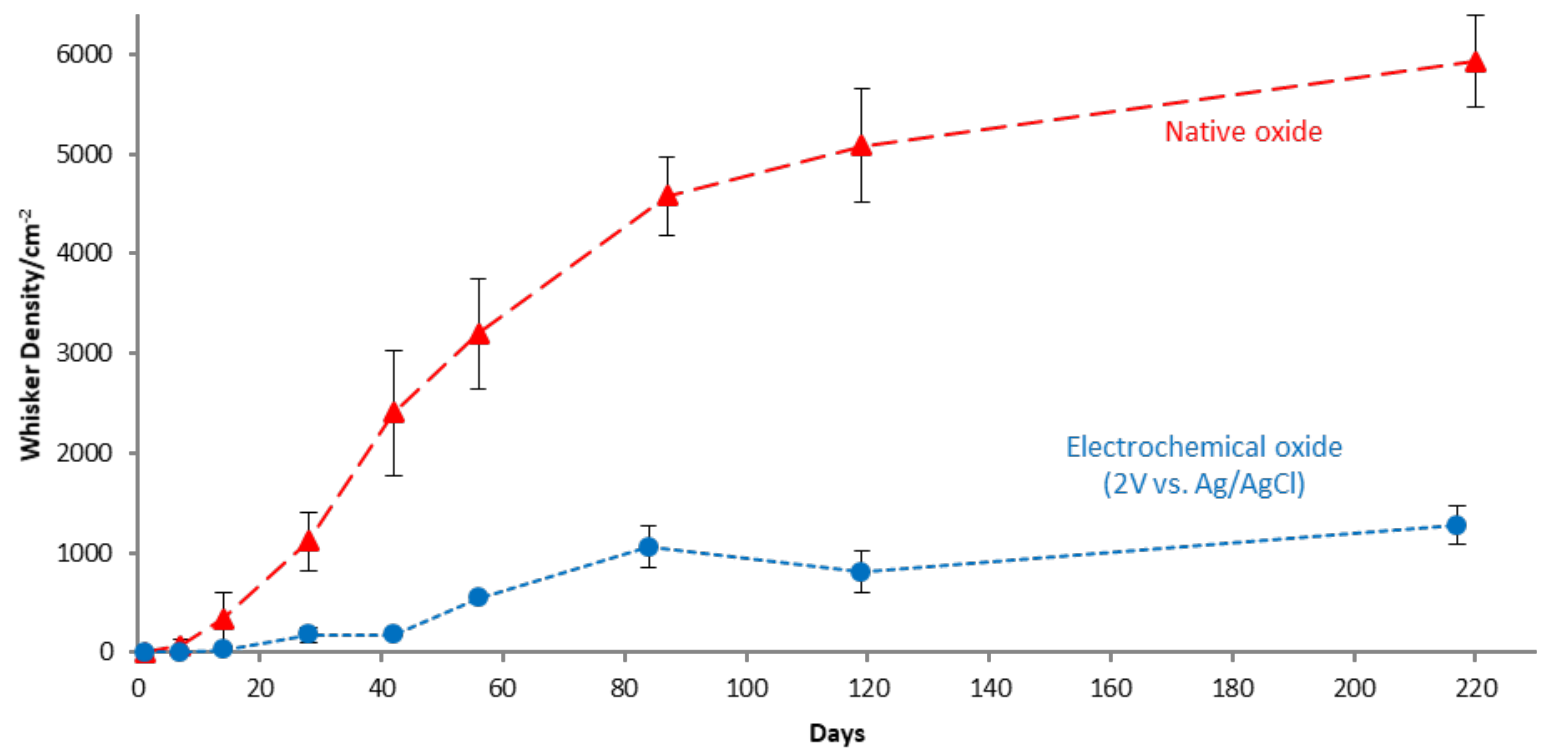


Fig.9

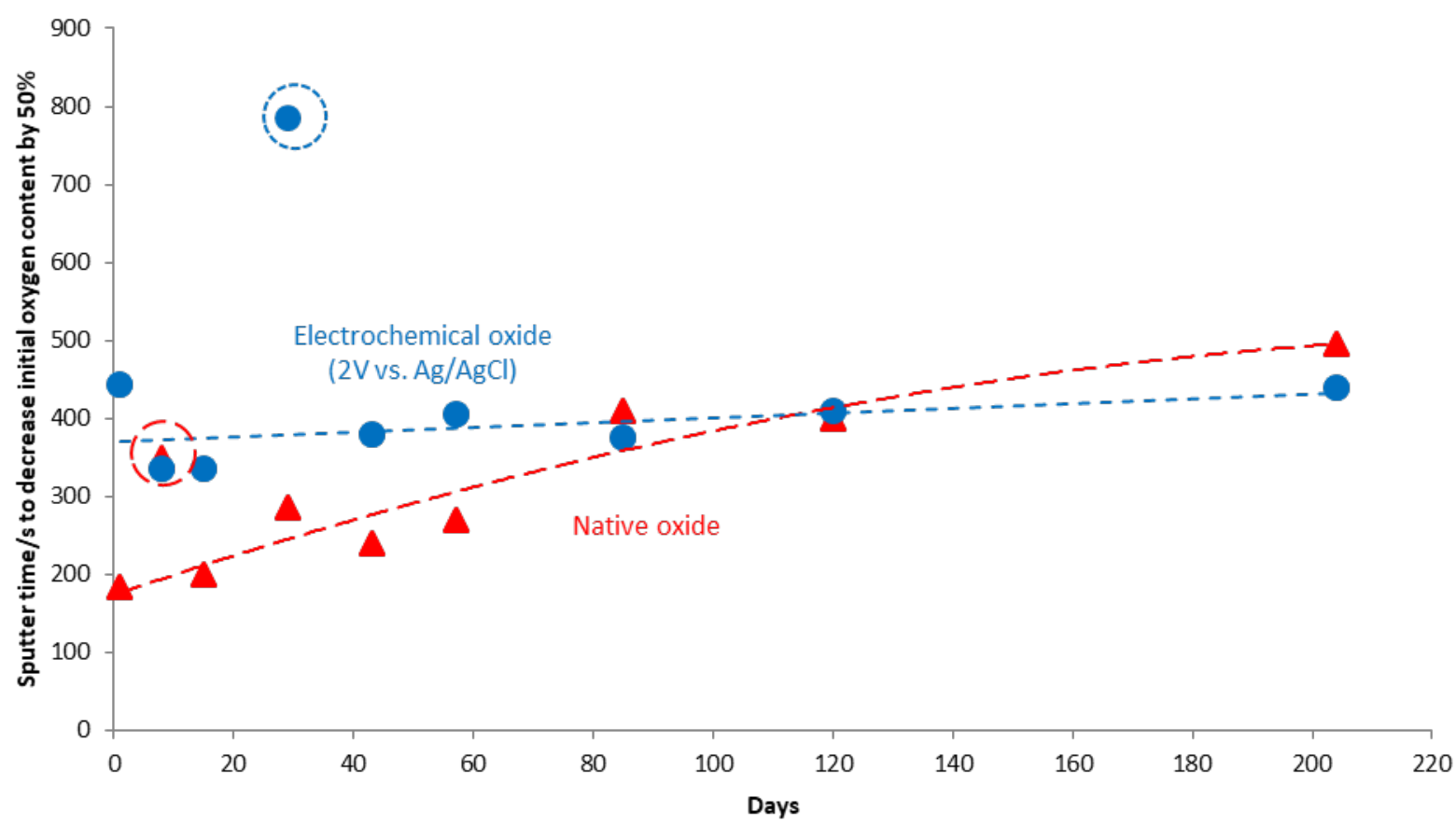


Fig.10

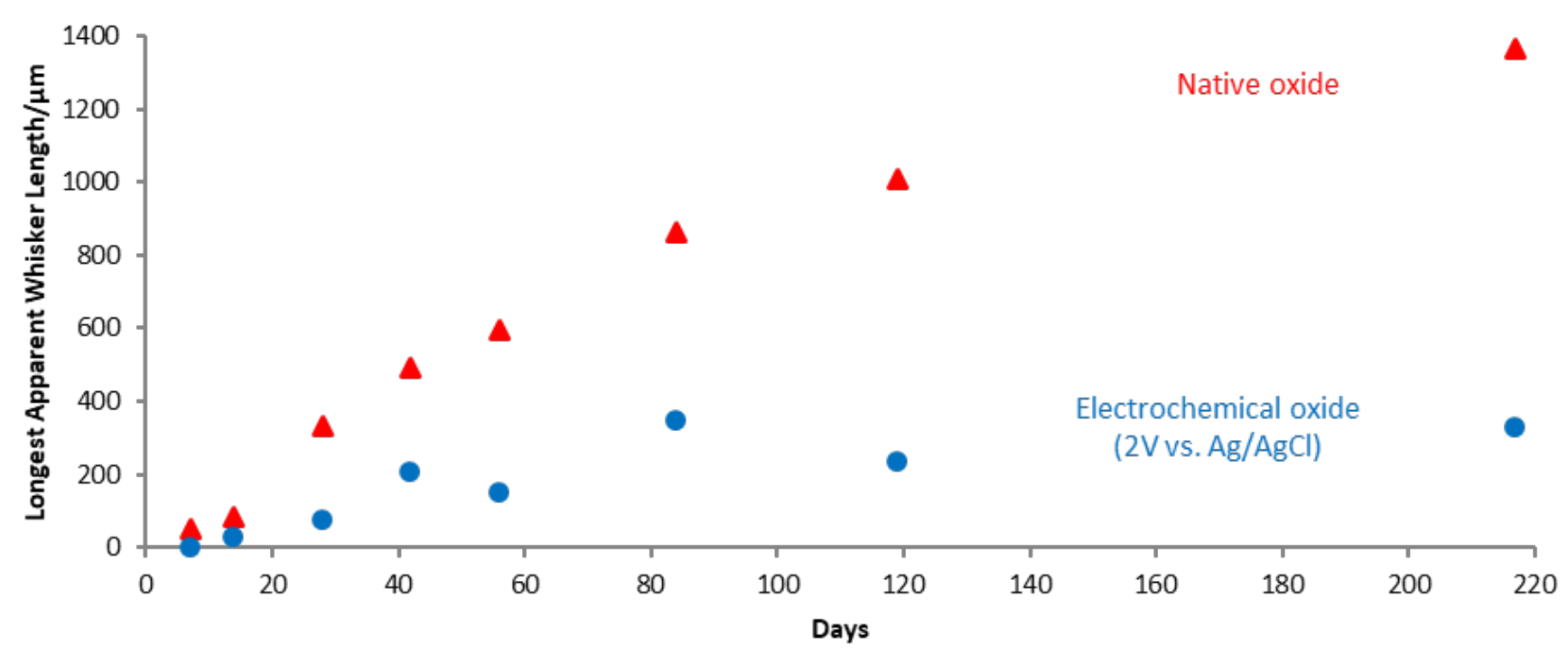



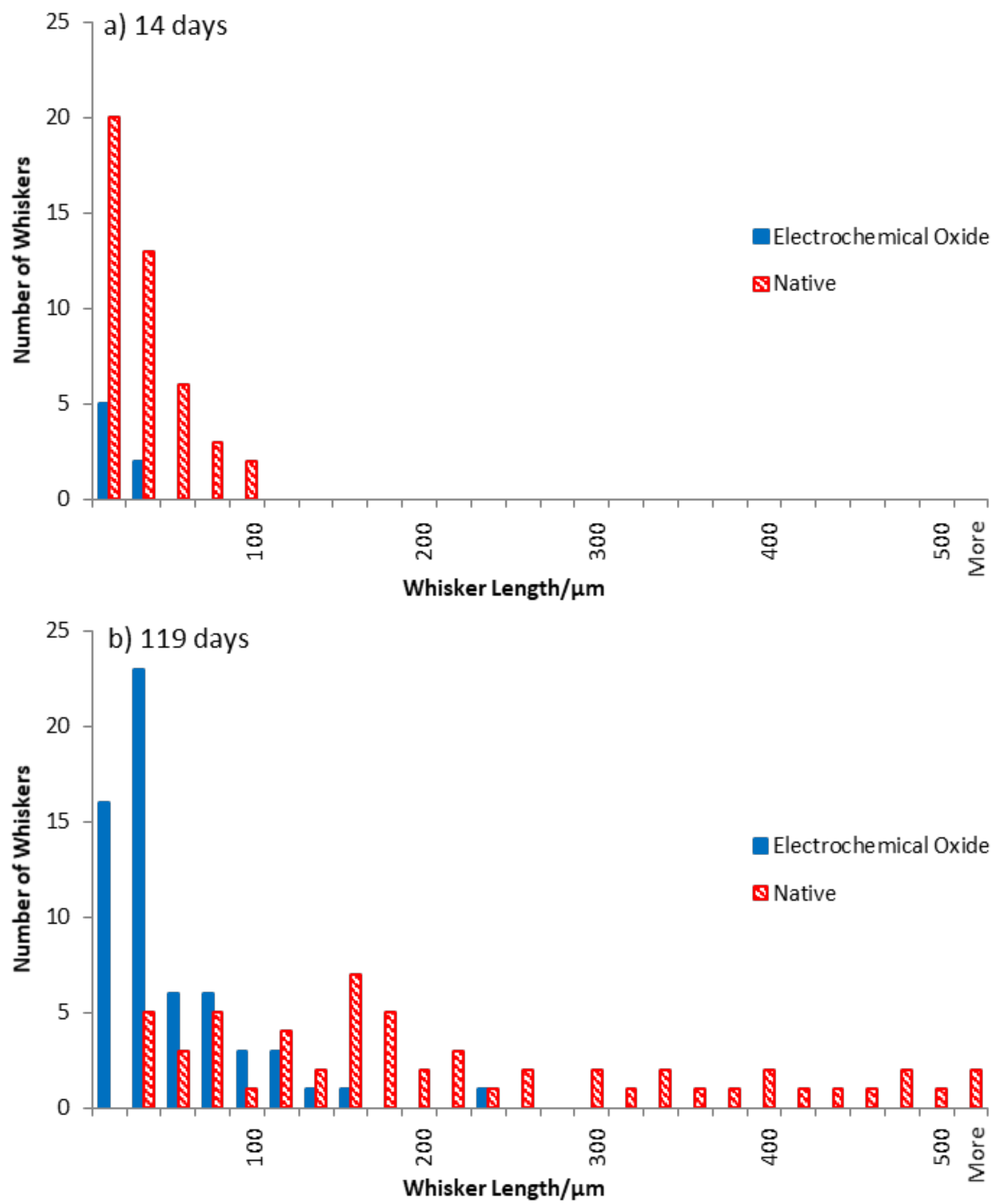
Fig.12

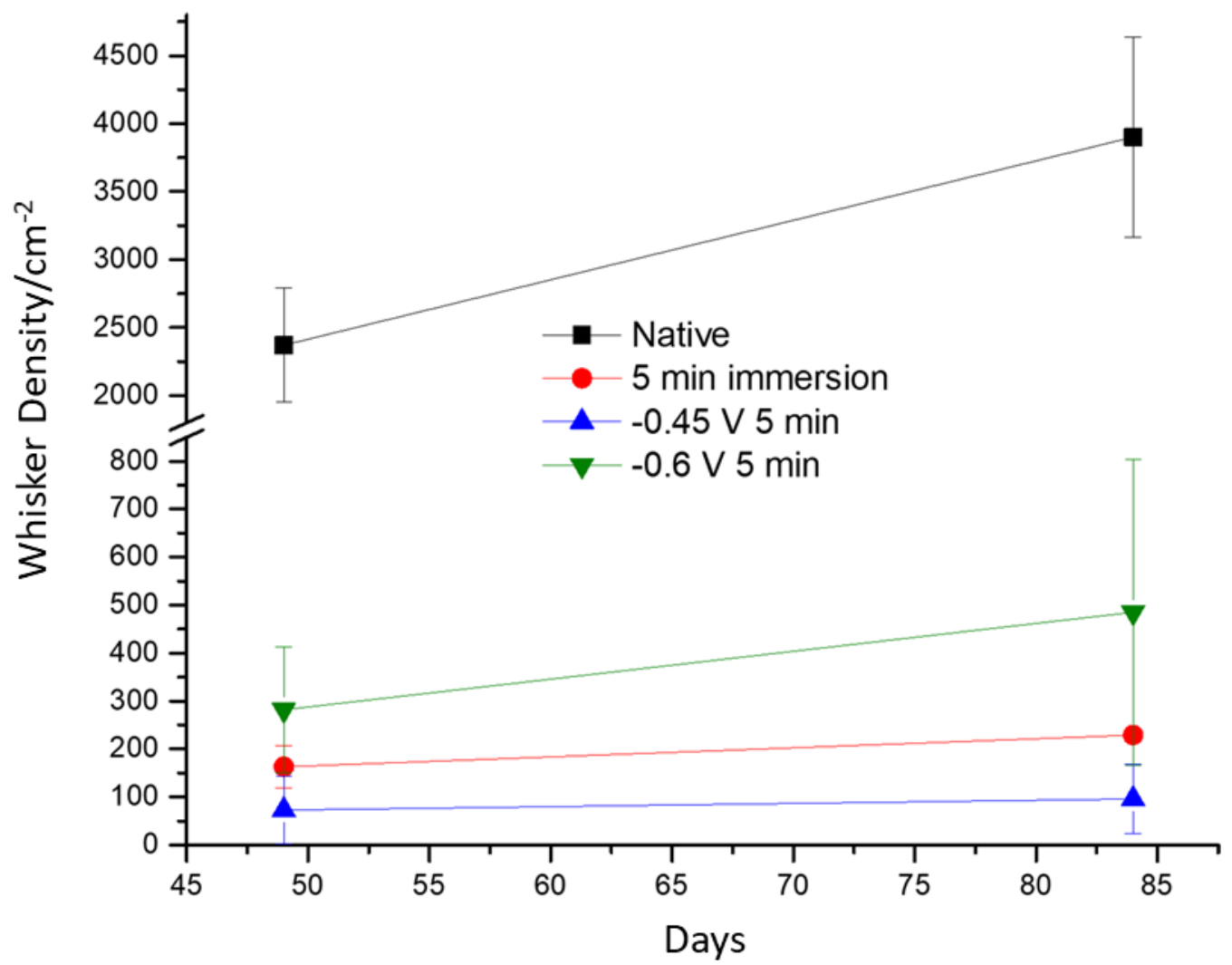


Fig.13

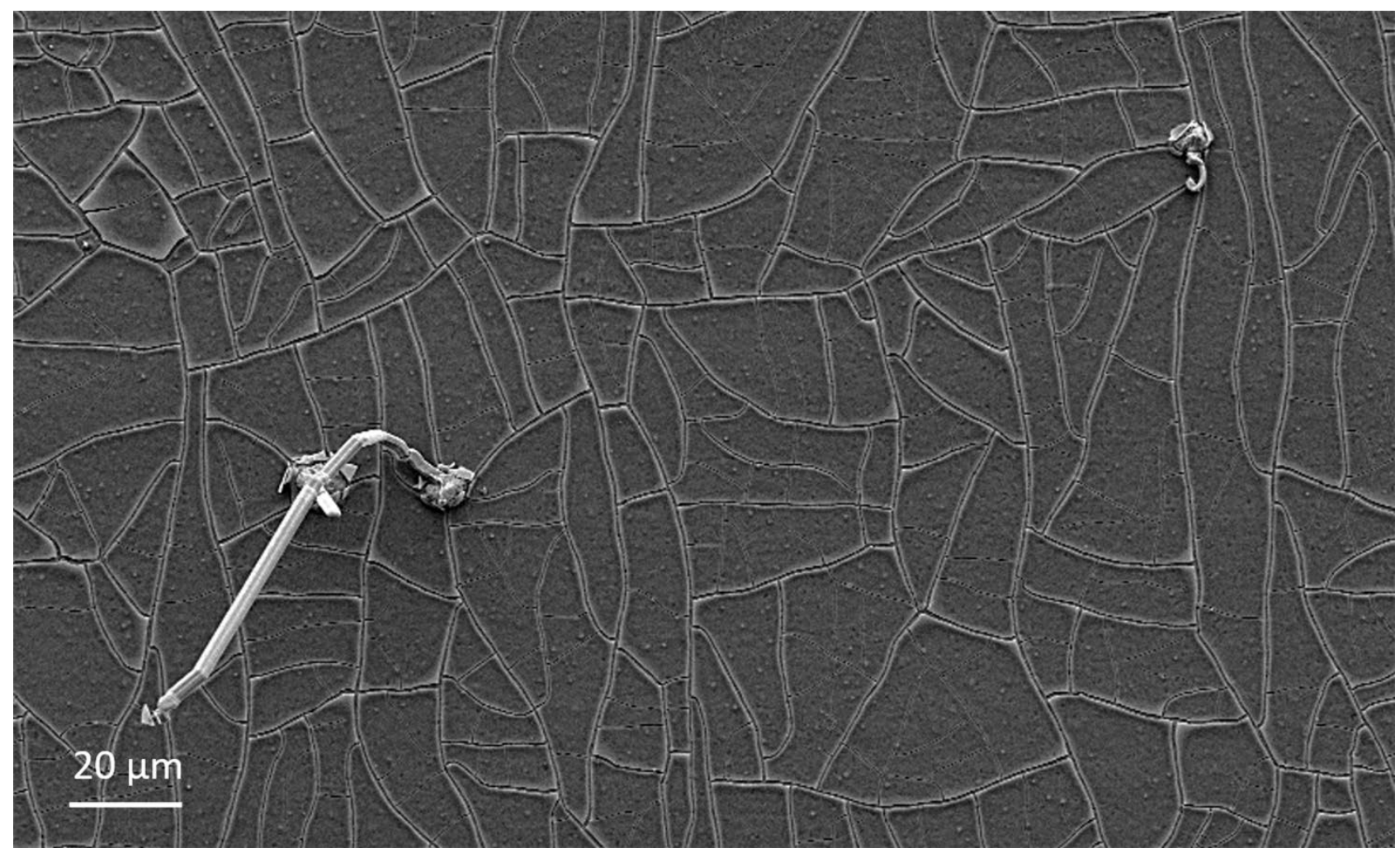


Fig.14

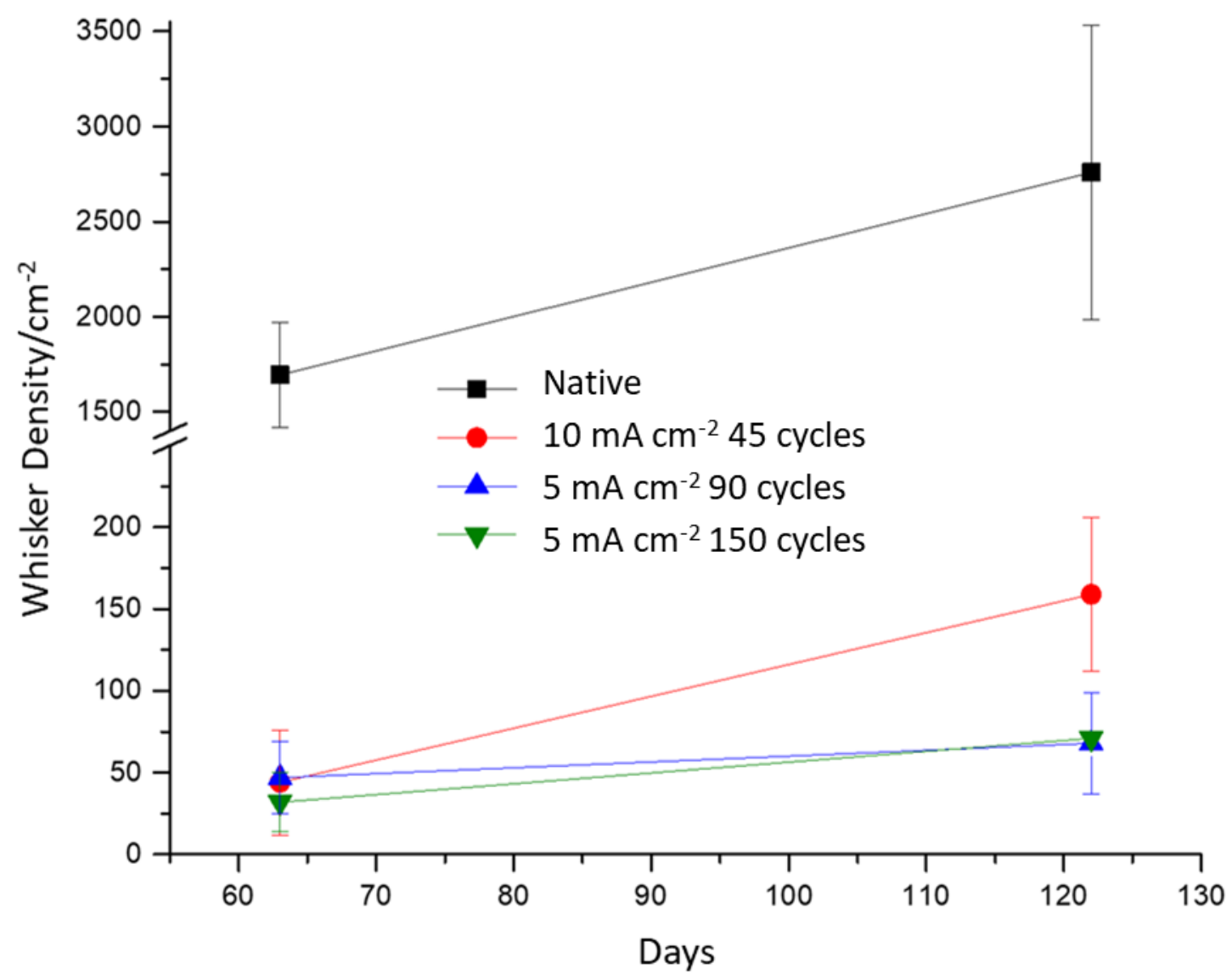


Fig.15
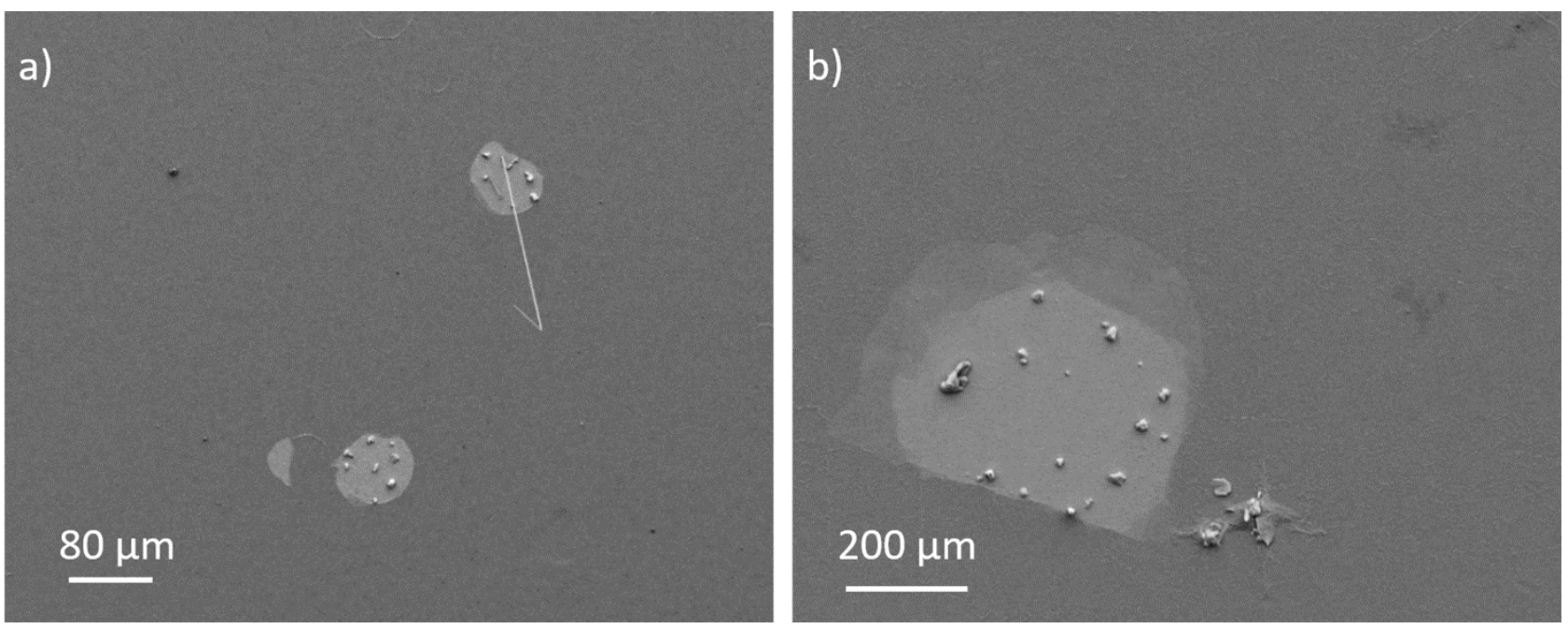
Fig.16

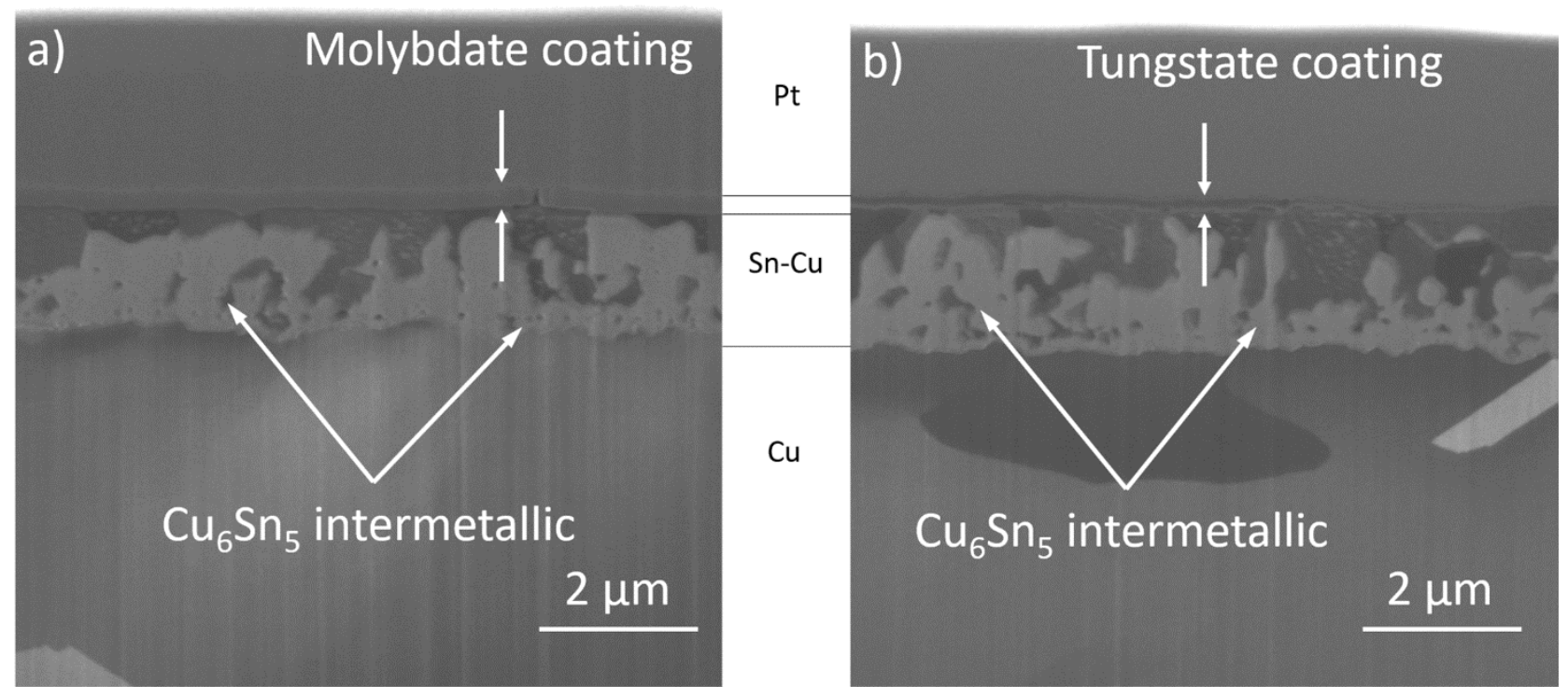

